1 Chapter 15.

2

\title{
Review on modelling approaches based on computational fluid dynamics for biomass pyrolysis systems
}

\section{Przemyslaw Maziarka, Frederik Ronsse, Andrés Anca-Couce}

\begin{abstract}
Modelling is a complex task combining elements of knowledge in the field of computer science, mathematics and natural sciences (fluid dynamics, mass and heat transfer, chemistry). In order to correctly model the process of biomass thermal degradation, in-depth knowledge of multi-scale unit processes is necessary. A biomass conversion model can be divided into three main submodels depending on the scale of the unit processes: the molecular model, single particle model and reactor model. Molecular models describe the chemical changes in the biomass constituents. Single-particle models correspond to the description of the biomass structure and its influence on the thermo-physical behaviour and the subsequent reactions of the compounds released during decomposition of a single biomass particle. The largest scale submodel and at the same time, the most difficult to describe is the reactor modef, which describes the behaviour of a vast number of particles, the flow of the reactor gases as well as the interaction between them and the reactor. This chapter contains a basic explanation about which models are currently available and how they work from a practical point of view.
\end{abstract}

\section{$\underline{\text { Affiliations }}$}

Przemyslaw Maziarka, Frederik Ronsse (corresponding author)

Department Green Chemistry and Technology, Gent University, Ghent, Belgium

E-mail: Frederik.Ronsse@UGent.be

Andrés Anca-Couce,

Graz University of Technology, Graz, Austria

E-mail: anca-couce@tugraz.at

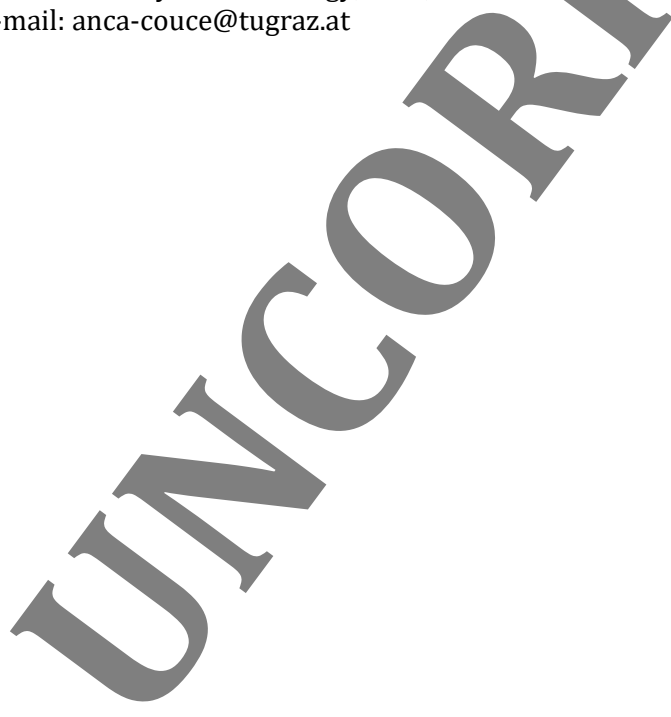


One of the most important processes of primary biomass conversion into carbonaceous materials is pyrolysis. It can be defined as the thermal conversion of biomass in an atmosphere with no oxygen to prevent its burnout. The "idea" of this process is not a new concept and has been known since ancient times [1]. As one can presume, these traditional technologies are based on very basic solutions, like kilns or burning pits, which are simple in use, but their efficiency and process control are relatively poor. In the past, the knowledge about the conversion process itself was not profound and did not allow for significant improvements in the technology. In the last four decades, due to social pressure favouring renewables and though research initiatives, the knowledge gaps started to fill, and new, more efficient solutions started to appear. Unfortunately, despite the increasing pressure for replacing fossil fuels, the alternative materials produced using novel renewable technologies are in many cases not sufficiently engineered, or their price is uncompetitive on the current market. For this purpose new and more sophisticated methods of research as well as new technological ideas, including modelling, are being developed to meet both economic and engineering ends of the problem.

\subsection{Biomass conversion - the modeller's approach}

\subsubsection{General overview of simulation and its uncertainties}

Substantial improvements in computer science in the last 30 years eased and spread access to a robust tool - numerical modelling. Simulations conducted on numerical models have allowed to significantly improve the pace of research and development in the biomass processing field.

Some commonly used terms need to be defined and clarified before the topic of computational modelling can be dealt with. A "model" is the mathematically described (by algorithms and equations) representation of a system existing in real life, and a "simulation" is an act of performing a test on a model. The term "numerical" means that the mathematical model will be translated through informatics into a numerical language, known by a numerical tool (more straightforward, a computer) to perform the computations [2]. Models can be various, depending on the field where they are used, but in natural sciences and engineering, the most commonly used ones are numerical models.

A simplified scheme of a simulation study with the linkage between the experiments, theory, and model is shown in Fig. 15.1. As can be seen in this figure, the simulation has to be validated to obtain proof of its usefulness. Models based on experimental data are reliable only in a specified range of experimental values and only for this range results are valid. In general, it is always better to set the foundation of the model on fully established theories, which have a broader range of validity.

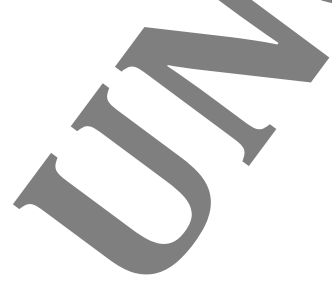



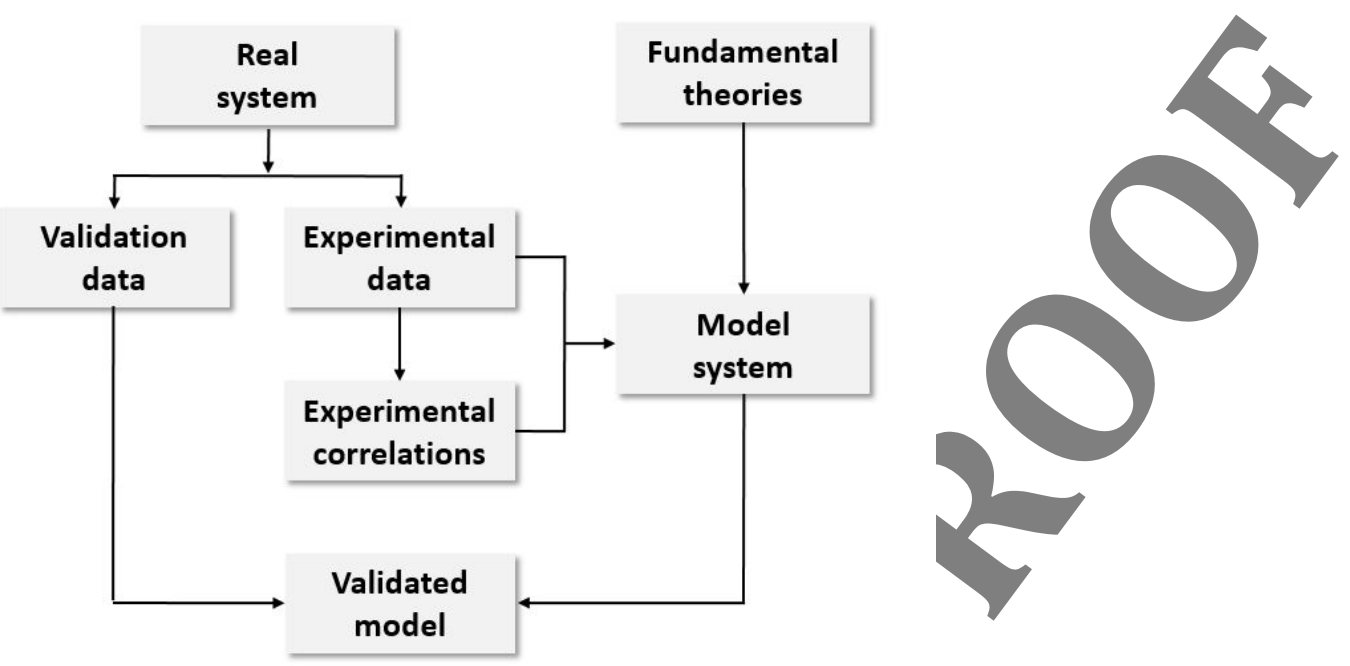

Fig. 15.1 Simplified scheme of a simulation study (adapted from [3]).

It needs to be kept in mind that models are only a representation of a real system, and in most cases they include simplifications and approximations. Moreover, the model background lies often in experimental data, which could be burdened with errors. Therefore, simulation results in most cases show discrepancies from "true/real" results, caused by unknown deviations of the model elements. These deviations are known as "uncertainties". To be able to bring the model result's closer to reality, the uncertainties need to be found, quantified and clarified. The sources of uncertainty can be divided into [4]:

- Parameter uncertainty - related to the parameters used in the model, which cannot be experimentally measured (too hard or too expensive) and have to be assumed in the model

- Model inadequacy - lack of full knowledge about the theory behind the modelled system or influence of the simplifying assumptions

- Residual variability - simulation output differs from experimentally obtained results through random fluctuations of parameters in a real situation (low repeatability of the real system)

- Parametric variability - the-modelled system is not sufficiently described/measured, and input values have to be assumed

- Observation error (experimental uncertainty) - stemming from deviation in values due to the variability of experimental measurements

- Interpolation uncertainty - related to the assumption of the parameter trend in the range of experimental results between two consecutively measured data points

- Code uncertainty (numerical uncertainty) - the strongest uncertainty related to numerical procedures, caused by the inability to exactly solve the problem (technical boundaries) and the use of approximations while solving, e.g., in solving partial differential equations by a finite element solution method

A clear indication of the individual share of each uncertainty on the total uncertainty is not simple if at all possible, because of their strong interdependencies. For example, application of thermophysieal data from literature can influence parametric variability and residual variability. The initially implemented experimental correlations in the model and the simplification of a real system introduce model inadequacy, and the model's validation with its consecutive adjustment to experimental data can increase the residual variability and the observation error. Proper clarification of errors can improve the modeller's awareness about possible flaws within the model. Modellers are advised to keep a critical and very careful approach due to the possible implementation of unknown (unexpected) errors. The aforementioned errors, after implementation, are usually difficult to identify and time-consuming to remediate. 
Simulations on a properly constructed model provide valuable information about the system behaviour, which often cannot be obtained through experimental measurements. Such knowledge can give a significant boost for the development of innovative solutions and helps to identify the critical points within the system (bottlenecks). In general, the use of modelling studies brings four main advantages [2]:

- Allows for conduction of proof-of-concept (PoC) at the very beginning of the project (low sunk cost in case of failure)

- Allows for a performance of numerous tests with a low unit cost

- Increases the knowledge about dependencies in a real system

- Accumulates the obtained datasets and simplifies their treatment and sharing (big data processing)

All of the mentioned advantages can have a crucial impact on the economic feasibility of new technological solutions. As it is shown in Fig. 15.2, the application of simulations can reduce the overall cost of new solution implementations and reduce the risk of the project's unprofitability, which in the development of new technologies is a strong benefit.

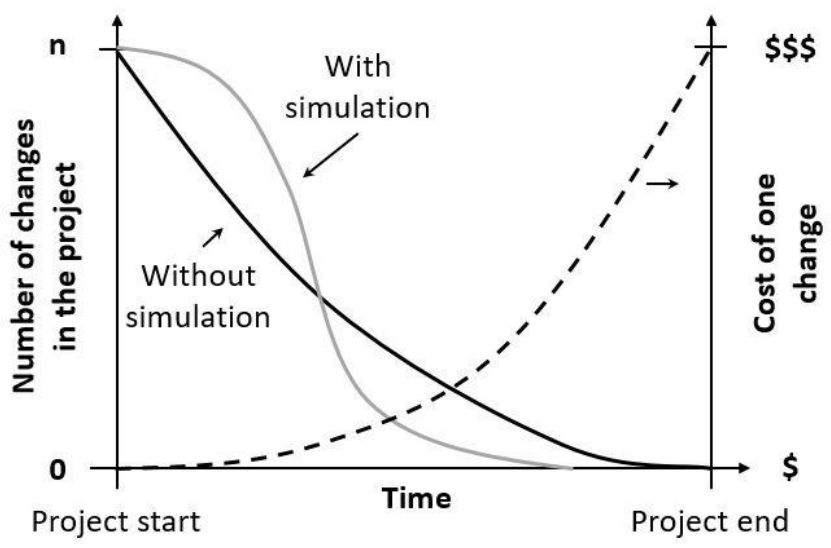

Fig. 15.2 Changes to the new idea implementation costs, through the project time (adapted from [2]).

Models are more flexible than real processes, so changes in modelled systems and their influence can be quickly verified. The modelallows for solving technical problems in the early stage, which is the lowest cost extensive option. Modelling can also expand the knowledge about the investigated process. If the model is detailed and mimics the real system well, there is a possibility to investigate and validate new correlations and theories through large and detailed databases of the process history.

\subsubsection{Theoretical framework of a comprehensive model for pyrolytic biomass conversion}

As it is illustrated in Fig. 15.3., a comprehensive/multi-scale model for biomass conversion can be divided into few submodels according to the scale in which the crucial processes take place. Besides combined implementation, each submodel can be studied separately, experimentally or through simulation, leading to expanding the knowledge of certain biomass conversion phenomena. 


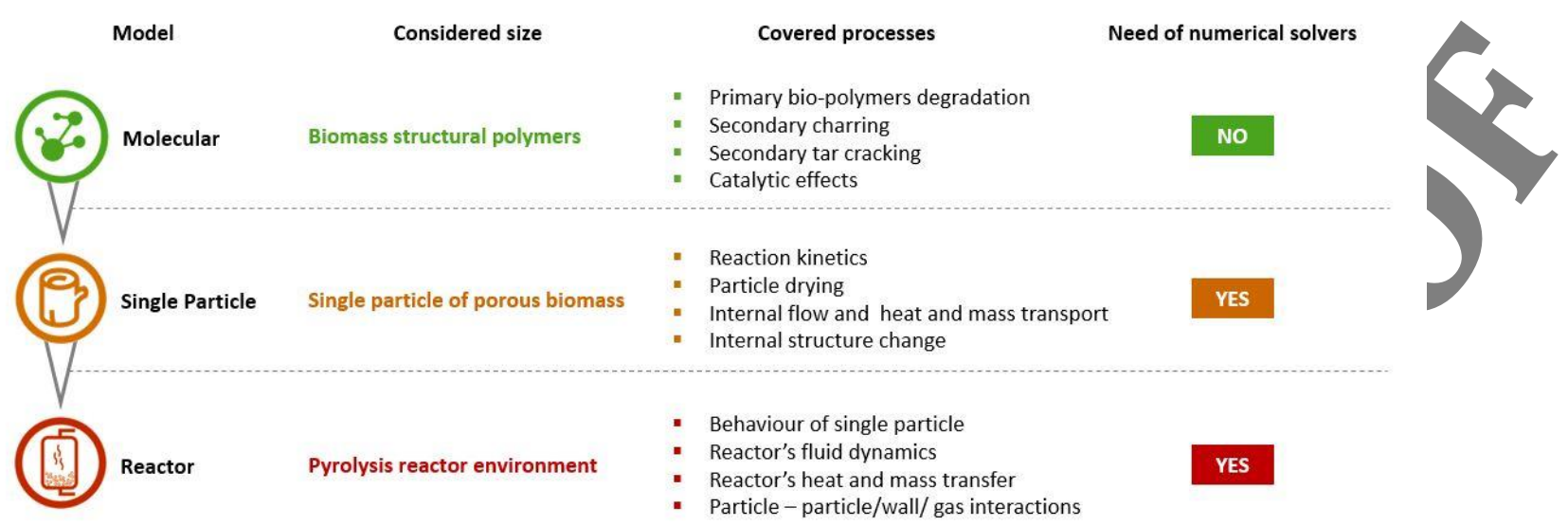

Fig. 15.3 Framework of a comprehensive biomass conversion model (adapted from [5]).

The smallest considered scale in a comprehensive model is the molecular model. It describes the chemical reactions of organic compounds and catalytic effects of inorganic compounds which take place during biomass conversion. Chemical reactions themselves are not necessarily bound to spatial dimensions, so the implementation of geometry (i.e. biomass particle) can be omitted. The amount of data which is used for this model scale allows for simulations without the need for robust numerical solvers.

A submodel covering a larger size is the single-particle model. It describes the behaviour of one individual biomass particle for which temperature, species concentration and pressure gradients during the process play a crucial role. A single-particle model needs to contain a description of the heat and mass transport phenomena and fluid dynamics. The model may cover changes in particle size, shape and structure (porosity) as well as bio-polymers chemical reactions and water evaporation processes. The particle properties, intra-particle processes and boundary conditions have a strong influence on the final products yield and composition [5]. Therefore, the intraparticle phenomena, as well as their chemistry, has to be described in a very detailed manner. In the model, the gases and liquids are treated as fluids and biomass as a stagnant solid. The Eulerian description (see later) is sufficient to cope with such physical behaviour for both phases. The single particle model is strongly dependant on the geometry, so the use of a numerical solver is necessary to perform simulations at this stage.

The last submodel of a comprehensive biomass conversion model is the reactor model. It covers the description of every relevant process in a reactor for biomass thermochemical conversion. The behaviour of each biomass particle in most cases should be, if possible, described separately with a single-particle submodel. Besides the particles' conversion, the model also consists of flow and thermal behaviour of gases, particles movement (collisions with each other and walls) and thermo-physical interactions between gas and solid phases. Therefore in the reactor model, the Eulerian description of fluids needs to be combined with biomass particles movement described with a Lagrangian approach (more complex and precise, simultaneously harder and more computationally extensive option), or with an Eulerian approach (this simplification is not always possible and valid but less complex and less computationally burdening). The quantity of equations and the amount of data needed to be processed in the reactor submodel is the largest among all submodels of a comprehensive biomass conversion model. To perform simulations in an efficient manner, the model requires appropriately large computational power resources, adequate to the chosen sub-models and their complexity. 


\subsubsection{Brief overview of biomass composition}

Before the description of chemical reactions that occur in biomass during thermochemical conversion, a brief explanation of biomass composition should be made. There are several biomass sources such as wood and woody biomass, herbaceous and agricultural residues, starchy crops, oil crops, aquatic biomass and, animal and human biomass wastes. The most commonly employed biomasses for energetic purposes, such as woody biomass, herbaceous biomass or agricultural residues, have a lignocellulosic structure. In lignocellulosic biomass, organic matter is mainly made from 3 main structural biopolymers: cellulose, hemicellulose, lignin and other, minor compounds which are organics named extractives and inorganics called mineral matter. The concentration of each substance varies with biomass type, and even within the same species, they are distributed in different ways among the plant organs (e.g. leaves, stem, bark, roots in wood) [6]. Detailed characterisation of the structure of bio-polymers and their thermal degradation has been extensively investigated and can be found in numerous literature reports [7-22].

\subsubsection{Single component and competitive schemes}

Historically, the description of the pyrolysis reaction started with the introduction of simple biomass thermal degradation models. Those models are largely based on mass-loss data obtained in thermo-gravimetric (TG) experiments and up to this day are very common among researchers due to their simplicity. The core of said models is the biomass degradation kinetic, in which biomass is treated as a bulk material. Those models only take into consideration the primary biomass degradation reactions. Models based on TG show strong fluctuations between publications in obtained kinetic values. Differences can be caused by using feedstocks with different bio-composition, size, and morphology as well as by the applied methodology and calculation procedures [5]. In order to systematise TG measurements, the International Confederation for Thermal Analysis and Calorimetry (ICTAC) presented guidelines for an experimental procedure for kinetic investigations, including researches related to biomass degradation [23]. Discrepancies between the kinetic data among publications can also be caused by inappropriate assumptions regarding the kinetic mechanism. In most cases, TG models consider only the primary biomass degradation and they do not take into account the lowtemperature tar-char interactions $\left(<500^{\circ} \mathrm{C}\right)$. Additionally, the secondary charring reactions in most TG-based models are not distinguished nor considered. Those reactions are usually lumped together with the primary degradation reactions, which leads to a shift in the value of primary kinetic parameters and as such, discrepancies in values between sources. A detailed overview of the experimental approach of a mass-loss based biomass degradation study can be found in a recent and comprehensive review by Anca-Couce [5].

Introduction of the single-component competitive models led to an improvement of TG models accuracy. Those models, besides prediction of mass loss, aim to predict also the three main products of biomass pyrolysis: char, tar, and gas - without distinction on their detailed composition. Single-component competitive models are covering only primary biomass degradation reactions, which have an influence on the prediction accuracy of product's yields [24]. Further development of the single-component competitive models was made by the introduction of cracking reactions of high molecular mass vapours (tars) at temperatures higher than $500{ }^{\circ} \mathrm{C}$ [25]. The most often used kinetic scheme is the one proposed by Shafizadeh and Chin [26].

When a higher prediction accuracy is required, the degradation of individual biomass components has to be considered in the kinetic scheme. Such schemes are named the multicomponent parallel schemes, and they cover the degradation of the main biomass components 
(e.g. cellulose) and their intermediary products [27]. In literature extensions and improvements of the original Shafizadeh and Chin's competitive scheme can be found, e.g. via the addition of intermediate compounds or considering the three main biomass constituents. Nevertheless, the expanded models show only moderate improvement regarding the accuracy in model prediction $[28,29]$. For more detailed outcomes, kinetic schemes need to cover the description of the thermal degradation of all bio-components, combined with a description of the consecutive degradation of the primary pyrolysis products.

\subsubsection{Detailed reaction schemes: Ranzi scheme}

A more detailed description of biomass degradation in a kinetic scheme was first introduced by Ranzi et al. [30], and was further improved by him and co-workers [31-35]. The most recent extension of the model was published by Debiagi et al. [36], which improves the accuracy of the prediction of char yield. In general, the Ranzi model combines all findings related to the thermal decomposition of each major component of biomass: cellulose, hemicellulose ( 2 types), and lignin $[11,16,37]$. In the scheme, the overall lignin is divided into 3 artificial types of lignin: LIG-H, LIG0 , and LIG-C (hydrogen-, oxygen- and carbon-rich, respectively). Another innovation of the Ranzi model is a description of char, which distinguishes "pure" char and the volatiles "trapped" within a char metaplastic phase. Thermally unstable "traps" degrade according to the applied kinetic, releasing captured volatiles. Such a description allows for the introduction of the char devolatilisation into the kinetic scheme. The Ranzi model does not cover all possible evolved species in pyrolysis, but reduces their amount to 20 representative volatile compounds, being the most abundant in non- and condensable vapours. The Ranzi scheme allowed for the derivation of a complex reaction scheme, combining separate mechanisms into a consolidated form. The latest version of the composition of vapours, kinetic parameters, and the reaction heats can be found in the work of Ranzi et al. [34,35].

The Ranzi model is a milestone in the description of pyrolysis kinetics, but there are a few areas in which improvements or extensions can be made. The kinetic scheme was developed for a description of fast pyrolysis, so it does not cover the secondary charring reactions. Moreover, it does not consider the catalytic influence of the of mineral matter (mainly AAEM's) contained in biomass, which leads to overprediction of the sugars and underprediction of the non-condensable gases and char. Also, the pyrolytic mechanism of the evolution of phenolic compounds is not contained in the base scheme, causing an underprediction of BTXs at higher temperatures $[5,19]$. Accuracy improvement can be made by the implementation of secondary cracking reactions of the primary pyrolysis products in the gas phase. For example, it can be done by the implementation of the POLIMI kinetic mechanism, developed by the CRECK modelling group, recently revised by Ranzi et al. [35]. The POLIMI kinetic mechanism is a complex, radical, kinetic scheme, whose application improves the accuracy of prediction, but is also time-consuming to implement and increases the computational burden significantly.

\subsubsection{Detailed reaction schemes: Ranzi - Anca-Couce model}

As was mentioned in the previous section, the Ranzi model was intended for the prediction of products from fast pyrolysis, so it shows some limitations in terms of describing biomass conversion in less severe thermal regimes. Lower thermal gradients or extended gas-solid reactions, e.g. in pyrolysis of larger samples, can lead to losses in prediction accuracy in case of application of the Ranzi model. An extension of secondary charring reactions to the Ranzi scheme, named as RAC (Ranzi - Anca-Couce) scheme was introduced by Anca-Couce et al. [19]. Their adaptation aimed to incorporate the secondary charring phenomena with the possibility of their adjustment to the severity of the conversion regime. A full description of the model with its kinetic parameters and reactions heat values can be found in the works of Anca-Couce et al. [19,37]. 
The RAC model introduces an adjustable parameters " $x$ " which defines the share of the alternative degradation, named "charring" or "secondary charring" in the overall degradation process. The adjustable parameter also partially takes into account the influence of inorganics which have a role in promoting "charring" reactions. As the main factors which increase the extent of charring, the adjustable parameter value can be modified to account for [5]:

- Decrease in the pyrolysis temperature,

- Decrease in the heating rate,

- Increase in volatiles retention time in the particle (larger particle or slower gas movements),

- Increase of the pressure in the reactor,

- High concentration of the mineral matter, especially AAEMs.

The extent of secondary charring can be different for each bio-component, so the value of the " $x$ " parameter should be assigned separately. Unfortunately, lack of quantitative correlations between the pyrolysis conditions, biomass composition and amount of secondary charring reactions cause the need for the iterative fitting of the " $x$ " parameter to the experimental results. A common approach is to set the adjustable parameter for all bio-components $a$ priori, based on the available experimental data and then slightly adjust to the experimental result $[5,38]$. It is worth to mention that the amount of secondary charring reactions have as well a noticeable influence on the heat of the reaction, as it was observed by Rath et al. [39].

The RAC scheme also does not cover all areas which the Ranzi scheme lacks, e.g., a detailed description of AAEM's influence or insights into polycyclic aromatic compounds formation. The base RAC scheme does not take into account the secondary gas-phase tar cracking kinetics. As well as the Ranzi scheme, it can be extended with the POLIMI kinetic mechanism. Another possible option is the simple one-step kinetics firstly introduced by Blondeau and Jeanmart [40], and consecutively improved by Mellin et al. [41] and most recently by Anca-Couce et al. [42]. Application of the one-stage kinetic cracking scheme is relatively simple, and it improves the accuracy of predictions of the vapour composition.

Constant work and recent findings on the subject gives promise of improvement and further extension of the pyrolysis reaction schemes, which would allow for better understanding of biomass pyrolysis and the ability to predict its outcome with higher accuracy $[17,43,44]$. In table 15.1 is shown a brief summary of the comparison of kinetic models. As it can be anticipated, the more detailed the model, the better the accuracy of the predictions that can be attained. From the practical point of view, the application of a detailed model needs a lot more initial information about the processed feedstock. It also increases the complexity of the model, which leads to a higher computational burden. Therefore, the complexity of the calculation has to be chosen with caution, in relation to the desired precision of the model outcome.

Table. 15.1 Brief summary of the comparison of kinetic models

\begin{tabular}{ccc}
\hline & Detailed mass loss prediction & Detailed product composition \\
\hline Single component competitive scheme & No & Limited \\
Multi-component parallel scheme & Yes & No \\
Detailed schemes (Ranzi, RAC) & Yes & Yes \\
\hline
\end{tabular}

15.4. Single-pąrticle model

As was mentioned previously in section 15.2.3., the single-particle model focuses on the influence of the composition of a particle and its thermo-physical properties on the particle's behaviour during pyrolysis. The biomass particle, due to its structure, cannot be treated as an impermeable solid object, so the description of a porous structure needs to be implemented. In practical pyrolysis applications, the biomass is rarely fed to the process in a completely dry state. Therefore, 
besides the description of the pyrolytic behaviour, the drying process and description of water movement within the particle have to be included in single particle models.

Due to the geometrical dependence as well as the complexity of the phenomena occurring in this stage, robust numerical solvers have to be applied. Having in mind that the Eulerian approach is able to handle the description of the processes, suitable numerical tools have to be applied, such as the Computational Fluid Dynamics (CFD).

\subsubsection{Modelling conversion based on CFD}

Prior to the mathematical description of the thermo-physical phenomena occurring in the single particle, a brief explanation of CFD will be provided here. It should give the reader a basic insight in the Eulerian approach, which is applied in single particle models as well as in the modelling of gas flow at the reactor scale.

Computational Fluid Dynamics (CFD) is the analysis of systems involving fluid flow, heat transfer and associated phenomena (e.g., chemical reactions) by using computer-based simulation [45]. In general, CFD can be treated as the integration of the following fields: natural sciences (physics and chemistry), mathematics and computer science [46].

The model behaviour is based on governing equations - in which physical phenomena like transport phenomena are mathematically described through differential equations (e.g. NavierStokes equation). To solve the governing equations, high-level computer programs and software packages convert them with the use of computer programminglanguages to numerous, simple commands that can be understood by a computing machine.

CFD for its computation needs dimensional geometrical domains. As the first step of the model's construction, the initially specified geometry ("domain") needs to be subdivided into a finite number of smaller, non-overlapping subdomains called "cells". The process of dividing a domain into subdomains is called "meshing", and it results in a grid of cells ("mesh"), that occupies the whole geometry. The cell can be defined as a representative element or a representative volume, depending on the division method (finite element" or "finite volume", respectively). Geometry division techniques are already included in most commercially available CFD software packages. Each cell in the domain has a "node", which holds information about this certain area in the geometry. Information stored in the node changes according to the applied physical phenomena and chemical reactions.

The fluid dynamics principle employed in CFD means that it treats the flow of matter (fluid) as a continuum (Eulerian approach). In the Eulerian description of fluid dynamics, points in the geometry do not change their position with respect to the fluid motion $[47,48]$. The only change that occurs is the change of the values of parameters stored at specific, fixed points (nodes). Therefore, it allows only for a description of changes taking place in nodes in the investigated geometry. As a consequence, the approach makes no distinction of single molecules or particles, so their time-based investigation is not possible.

The accuracy and precision of a CFD simulation are determined by the number of cells contained in the grid ("mesh coarseness"). An increase in the number of cells improves a simulation accuracy, until the moment when a simulation becomes grid-independent. In other words, there exists a number of cells above which the addition of new cells no longer influences the simulation quality. The simulation is called a grid-independent simulation when further mesh densification does not lead to an improvement in solution accuracy [45]. Grid independent simulations have a major advantage, which is the smallest numerical error is achieved with the most coarse mesh (least computational burden).

A detailed explanation of the CFD solution procedure is complex and goes beyond the purpose of this chapter. Nevertheless, a brief introduction to the matter will be provided. A simplified scheme of data treatment and computing procedure in the CFD framework is shown in Fig. 15.4. The CFD framework consists of three main elements [46]: 
- Pre-processor - is a part of a CFD code that is responsible for the creation of an investigated geometry and its consecutive meshing. The mesh obtained in the pre-processor is a foundation for implementation of governing equations.

- Solver - through implemented solution methods, the solver simulates the changes of the variables in the nodes according to the applied governing equations and boundary conditions. The solver processes information regarding the applied physics and chemistry located on the nodes of the grid. Therefore, the solver is responsible for performing the simulation.

- Post-processor - is responsible for the visualisation of the simulation results. Most postprocessors allow for quick creation of 1D, 2D or 3D plots and representation of variables of interest on the applied geometry.

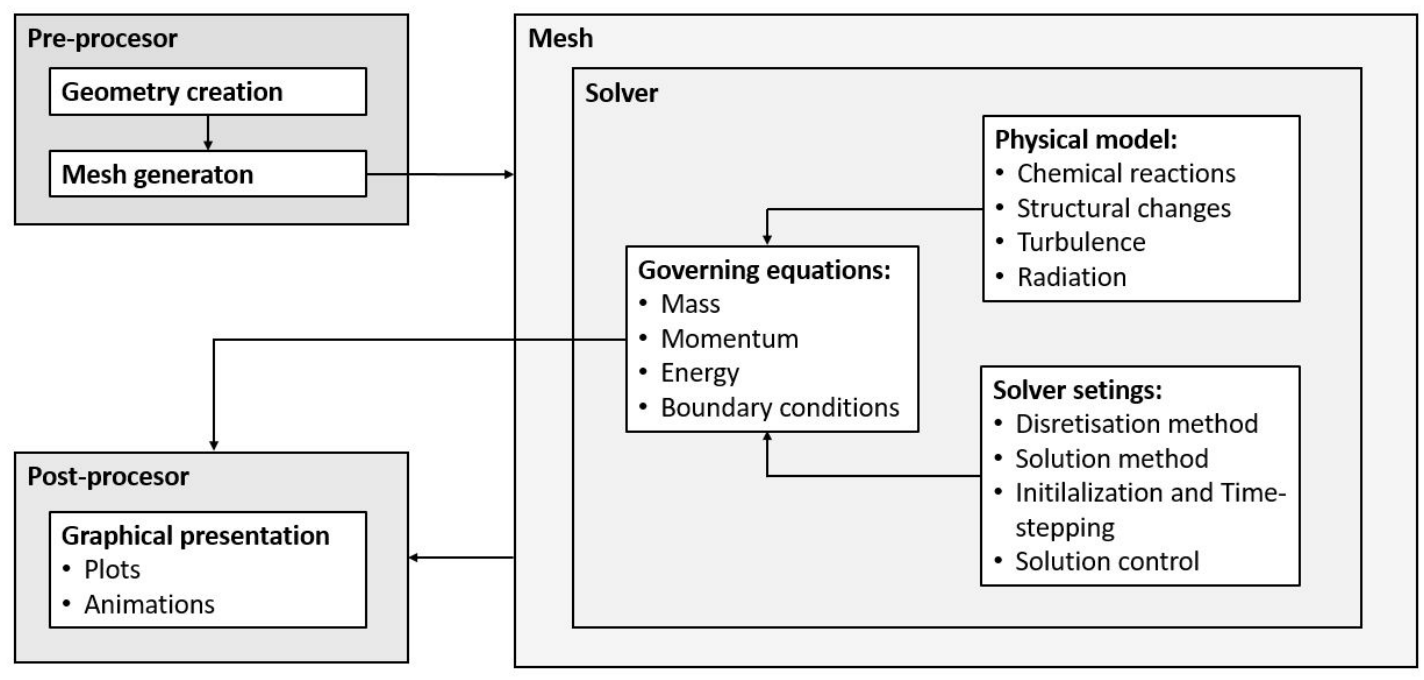

Fig. 15.4 CFD code solution scheme (adapted from [46]).

The CFD solution scheme as depicted in fig. 15.4 provides a general scheme, which is valid for any model based on the Eulerian approach. The specification of parameter values in the governing equations depend on the characteristics of the process which one needs to solve. Moreover, the reliability of a simulation's results is linked directly to data and auxiliary correlations, so to their compliance with the modelled system and range of application. Therefore further subsections will be focused on the reliable description of the phenomena occurring in the single particle models as well as the validity of the thermo-physical parameters applied in modelling of biomass pyrolysis.

\subsubsection{Definitions of phases in a particle's structure}

Biomass feedstock which has not been dried previously, and is typically used for conversion, consists in most cases of four different phases: liquid water, bound water, solid and gas. The bound water is distinguished from liquid water due to its significant difference in behaviour. Each of the mentioned phases needs to be identified and described separately.

A detailed theoretical description of each phase was first made by Whitaker [49], in which a boundary surface between each phase has to be differentiated and known during the whole process. Wood has a very complex geometric structure, which strongly changes during pyrolysis, so identification of boundary surfaces at every point in time is a very difficult and complex task. Also, the amount of computation for such a sophisticated model would be very high.

The efficient description of phases has been investigated by Perre and his co-workers [50,51], and on this basis, an elegant description of the system was presented in the work of Grønli [52]. In their approach, all of the phases are treated as a continuum for which conservation laws must be satisfied. The description assumes averaging of variables and parameters over a finite volume, 
which can simultaneously contain all phases. This results in a set of conservation equations for every phase, valid within the applied geometry.

For further model description, it will be helpful to define the spatial average over the geometry's total volume for any given variable $(\varphi)$ valid for every phase. The spatial average is defined as:

$$
<\varphi>=\frac{1}{V} \int_{V} \varphi d V
$$

The spatial average for one of the phases $(\gamma)$ is defined as:

$$
<\varphi>^{\gamma}=\frac{1}{V_{\gamma}} \int_{V_{\gamma}} \varphi d V
$$

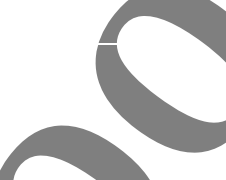

Where $\langle\varphi\rangle^{\gamma}$ is the variable 's averaged value in the phase $\gamma$ and $V_{\gamma}$ is the volume of the phase in the representative volume $V$. The volume fraction occupied by the phase $\chi$ is defined as:

$$
\varepsilon_{\gamma}=\frac{V_{\gamma}}{V}
$$

A relation between the averaged value in phase $\gamma$ and a spatial average is described as:

$$
<\varphi>=\varepsilon_{\gamma}<\varphi>^{\gamma}
$$

In other words, $\langle\varphi\rangle^{\gamma}$ is an intrinsic or true value of the variable and $\langle\varphi>$ is an averaged value in the representative volume. For example, if $<\rho_{S}>^{S}$ would be defined as the true density of the solid phase, then $\left\langle\rho_{S}\right\rangle$ will be defined as the density of contained solids in a representative volume of the porous particle structure (i.e. bulk density). The notation with the <,> brackets are based on the authors believe that it is clearer, and of course, it is not mandatory.

Since the particle is made in most cases out of four phases, the representative volume can be treated as a sum of volumes of each phase.

$$
V=V_{S}+V_{L}+V_{B}+V_{G}
$$

Where subscripts S, L, B, and G represent solid, liquid water, bound water and gas, respectively. Sum of volume fractions occupied by each phase sums into one, so:

$$
\varepsilon_{G}=1-\left(\varepsilon_{S}+\varepsilon_{L}+\varepsilon_{B}\right)=1<\left(\frac{<\rho_{S}>}{<\rho_{S}>^{S}}+\frac{<\rho_{L}>}{\left.<\rho_{L}\right\rangle^{L}}+\frac{<\rho_{B}>}{\left.<\rho_{B}\right\rangle^{B}}\right)
$$

Which means that knowing the intrinsic and average density of a solid, and both types of water, a volume fraction occupied by the gas can be calculated. Visual representation of a real system in the Whitaker theory is shown in Fig. 15.5.

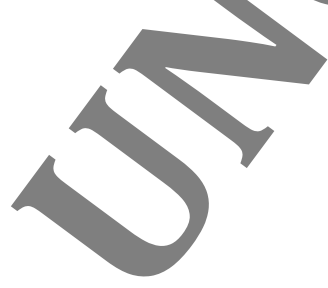




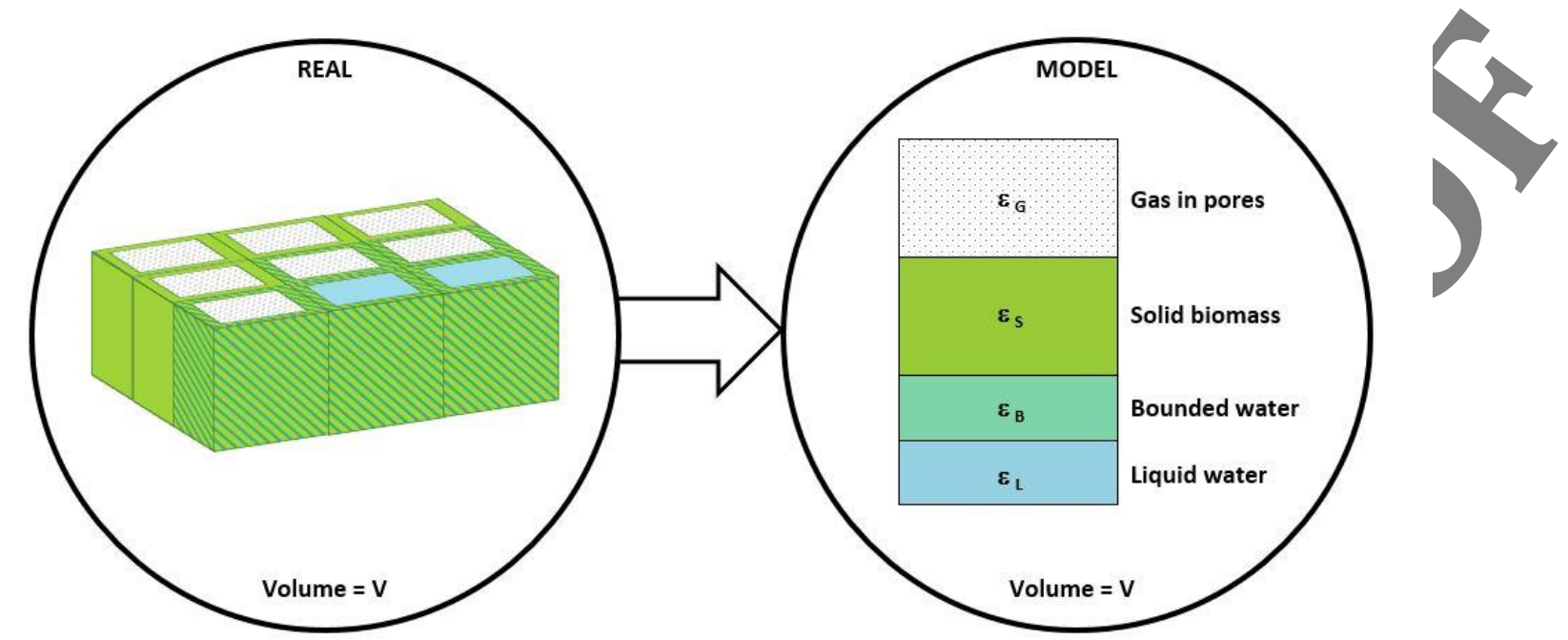

Fig. 15.5 Visual representation of the conversion of a real system (woody biomass) into a model system according to Whitaker's theory.

\subsubsection{Governing equations}

In this section, an explanation of the conservation laws will be provided. Nonetheless, the theoretical derivation of the formulas will be omitted. In here, the fundamental description of the mathematical description of the governing equations is applied. Therefore, the negative signs in the equations originated purely from mathematical derivations, and they are reflecting the actual values of parameters (positive or negative). All equations mentioned in this subsection are valid only within the applied particle geometry, and they do not describe the interactions of the particle with its external environment. Reading this subsection is worth to keep in mind that all conservation equations are referring to a single, fimite and representative volume.

For clarity purposes, the one component kinetic scheme will be used for explaining the principles. All kinetic schemes described in this section are treated as first-order Arrhenius kinetics with the pre-exponential parameter set as constant or temperature dependent. Additionally, from now on, wood will be treated as the exemplary lignocellulosic biomass type in the model description.

\subsubsection{Mass conservation equations: Solids}

At any given time of a pyrolysis reaction, the solid is represented by a mix of unconverted biomass and biochar, so it can be stated that:

$$
<\rho_{S}>=<\rho_{B M}>+<\rho_{B C}>
$$

Where $<\rho_{S}><\overrightarrow{\rho_{B M}}>$ and $<\rho_{B C}>$ are the volume-averaged densities of solid, biomass and biochar respectively. Mass conservation equation of biomass is defined as:

$$
\frac{\partial}{\partial t}<\rho_{B M}>=\dot{\omega}_{B M}
$$

Where $\dot{\omega}_{B M}$ is the mass change rate of biomass caused by degradation and devolatilisation reactions. Although the degradation reactions lead to a reduction in mass, a negative sign is not used in equation (15.8). Similarly, the mass conservation equation of biochar is defined as: 


$$
\frac{\partial}{\partial t}<\rho_{B C}>=\dot{\omega}_{B C}
$$

462 In most general form, the mass conservation equation is defined as:

$$
\frac{\partial}{\partial t}<\rho_{S}>=\dot{\omega}_{S}
$$

463

464

Where $\dot{\omega}_{S}$ is the total mass change of a solid obtained from a sum of the biomass degradation and char formation.

\subsubsection{Mass conservation equations: Single component in the gas mixture}

The equation for mass conservation of the $i^{\text {th }}$ component in a gas mixture is defined as:

$$
\frac{\partial}{\partial t}\left(\varepsilon_{G}<\rho_{i}>^{G}\right)+\nabla<u_{i} \rho_{i}>=\dot{\omega}_{i}
$$

Where $\left\langle\rho_{i}\right\rangle^{G}$ is the density of the $i^{\text {th }}$ component in the gaseous phase, $\left\langle u_{i} \rho_{i}\right\rangle$ is $i^{\text {th }}$ component's transport term and $\dot{\omega}_{i}$ is the mass change rate caused due to formation/degradation reactions of the $i^{\text {th }}$ gas component. Transport of the gas is driven by two phenomena: convection and diffusion. Therefore the transport term can be described as:

$$
<u_{i} \rho_{i}>=u_{G}<\rho_{i}>^{G}-<\rho_{G}>^{G} D_{e f f} \nabla\left(\frac{<\rho_{i}>^{G}}{<\rho_{G}>^{G}}\right)
$$

Where $u_{G}$ is the superficial gas velocity, $\left.<\rho_{G}\right\rangle^{G}$ is the total density of the gas mixture, $D_{\text {eff }}$ is the effective gas diffusion coefficient. The low permeability of biomass structures (small pores) leads to relatively low Reynolds numbers $(<10)$ for the gas movement inside a particle. Therefore the viscous resistance force is much larger than the inertial one, which simplifies the description of flow from Darcy and Forchheimer's description to a pure Darcy's description [53]:

$$
u_{G}=\frac{K_{G, e f f}}{\mu_{G}} \nabla\left(<P_{G}>^{G}\right)
$$

Where $K_{G, e f f}$ is the effective gas permeability, $\mu_{G}$ is the gas dynamic viscosity and $\left\langle P_{G}\right\rangle^{G}$ is the pressure in the gas mixture.

\subsubsection{Mass conservation equations: Liquid water}

Mass conservation equation for liquid water is defined as:

$$
\frac{\partial}{\partial t}<\rho_{L}>+\nabla<u_{L} \rho_{L}>=\dot{\omega}_{L}
$$

Where $<\rho_{L}>$ is the volume-averaged liquid water density, $\left\langle u_{L} \rho_{L}\right\rangle$ is its transport term and $\dot{\omega}_{L}$ is a mass change rate caused by evaporation or re-condensation. It is assumed that liquid water migrates through the structure entirely due to a pressure change (convectively), so its transport term is expressed as:

$$
<u_{L} \rho_{L}>=u_{L}<\rho_{L}>
$$

Where $u_{L}$ is a superficial velocity of the liquid water. Similar to the gas mixture, Darcy's law is also avalid to obtain the superficial liquid velocity: 


$$
u_{L}=\frac{K_{L, e f f}}{\mu_{L}} \nabla\left(<P_{L}>^{L}\right)
$$

486

487

Where $K_{L, e f f}$ is the effective liquid water permeability, $\mu_{L}$ is the liquid water dynamic viscosity and $\left\langle P_{L}\right\rangle^{L}$ is the pressure in the liquid water.

\subsubsection{Mass conservation equations: Bound water}

Mass conservation equation of bound water is defined as:

$$
\frac{\partial}{\partial t}<\rho_{B}>+\nabla<u_{B} \rho_{B}>=\dot{\omega}_{B}
$$

Where $\left\langle\rho_{B}\right\rangle$ is the volume-averaged bound water density, $\left\langle u_{B} \rho_{B}\right\rangle$ is the bound water's transport term and $\dot{\omega}_{B}$ is the mass change rate caused by water's unbinding. In opposition to the liquid water, it is assumed that the bound water migrates entirely by diffusion, so its transport term is:

$$
<u_{B} \rho_{B}>=-<\rho_{S}>D_{B} \nabla\left(\frac{<\rho_{B}>}{<\rho_{S}>}\right)
$$

Where $D_{B}$ is the bound water's diffusion coefficient.

\subsubsection{Energy conservation equation}

The energy conservation equation is based on the assumption that the Péclet number for heat transfer is sufficiently large, so a local thermal equilibrium is obtained by all phases [53]. Therefore the equation is defined as:

$$
\begin{aligned}
\frac{\partial T}{\partial t}\left(<\rho_{S}>C_{P, S}+<\rho_{L}\right. & \left.>C_{P, L}+<\rho_{B}>C_{P, B}+\varepsilon_{G}<\rho_{G}>{ }^{G} C_{P, G}\right) \\
& +\nabla T\left(<u_{L} \rho_{L}>C_{P, L}+<u_{B} \rho_{B}>C_{P, B}+\varepsilon_{G} \sum_{i=1}^{N}<u_{i} \rho_{i}>C_{P, i}\right)=\nabla\left(\lambda_{e f f} \nabla T\right)+Q
\end{aligned}
$$

Where $C_{P}$ is the heat capacity/specific heat and subscripts S, L, B and $i$ indicate solid, liquid water, bound water, and the $i^{\text {th }}$ component of the gas mixture, respectively, $\lambda_{\text {eff }}$ is the effective thermal conductivity and $Q$ is the total heat produced by the occurring reactions, and it is defined as:

$$
Q=\sum_{i}^{N} H_{i} \dot{\omega}_{i}+H_{L} \dot{\omega}_{L}+H_{B} \dot{\omega}_{B}+H_{S} \dot{\omega}_{S}
$$

Where $H$ is the oyerall heat of the reaction. In the most general case, the transport terms are implemented in the conservative form, so the energy conservation equation takes into account the heat transfer through conductive, convective and diffusion transport $[52,54,55]$. Some authors apply simplifications in defining the transport, by omitting the heat transported through diffusion, assuming that the amount of heat exchanged through this phenomenon is negligible [28,56-58]. Taking abovementioned simplification into account, the energy conservation equation takes the form:

$$
\begin{aligned}
\frac{\partial T}{\partial t}\left(<\rho_{S}>C_{P, S}+\right. & \left.<\rho_{L}>C_{P, L}+<\rho_{B}>C_{P, B}+\varepsilon_{G}<\rho_{G}>^{G} C_{P, G}\right) \\
& +\nabla T\left(u_{L}<\rho_{L}>C_{P, L}+u_{B}<\rho_{B}>C_{P, B}+u_{G} \varepsilon_{G}<\rho_{G}>^{G} C_{P, G}\right)=\nabla\left(\lambda_{e f f} \nabla T\right)+Q
\end{aligned}
$$

510 The mass change rate of every reaction in the kinetic scheme is defined as: 


$$
\dot{\omega}_{j}=k_{j}<\rho_{j}>=k_{j} \varepsilon_{\gamma}<\rho_{j}>\gamma
$$

511 Where $\dot{\omega}_{j}$ is the mass change rate of the $j^{\text {th }}$ species (e.g., biomass, tar, gas), $k_{j}$ is a reaction rate of

512

513

514

515

516

517

518

519

520

521

522

523

524

525

526

527

528

529

530

531

532

533

534

535

536

537

538

539

540

541 the $j^{\text {th }}$ species, $<\rho_{j}>$ is the averaged volume density of the $j^{t h}$ species and $\left\langle\rho_{j}\right\rangle^{\gamma}$ is the intrinsic density of the $j^{\text {th }}$ species in phase $\gamma$. Water can be an exception to this definition. Depending on the applied drying/evaporation model (equilibrium, heat sink, kinetic model) the mass change rate for the liquid and bound water will take a form suitable for the chosen model.

\subsubsection{Evaporation of water}

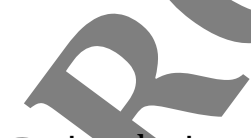

Moisture evaporation is one of the most energy-intensive phenomena occurring during pyrolysis of wet biomass particles. Therefore, its appropriate description has much importance. Three common ways of implementing biomass drying can be used in practice: the kinetic model, heat sink model and equilibrium model.

\subsubsection{Kinetic model}

The kinetic model represents the simplest way of describing evaporation. It was first introduced by Chan et al. [59], and then, due to its simplicity, it has been widely applied by other authors [6063]. The kinetic model assumes a first-order Arrhenius reaction of the liquid water phase turning into vapour. In work by Haberle et al. [64] a summary of the commonly used parameters for this model can be found.

The kinetic model is very convenient, but it treats a physical phenomenon via a chemical description, so it does not reflect the process well in real terms. In practice, in the kinetic model, water evaporation starts before water obtains its boiling temperature $\left(100{ }^{\circ} \mathrm{C}\right.$ at $\left.1 \mathrm{~atm}\right)$, and the temperature during evaporation does not stay constant during the whole process. Therefore, such a model may be suitable for specific cases, but it is not advised for general application.

\subsubsection{Heat sink model}

The heat sink model (thermal drying model, heat flux model) $[57,64,65]$ assumes that water evaporation in a representative volume occurs only at the boiling temperature, and the temperature stays constant until all water is evaporated. To maintain a constant temperature, the evaporation reaction needs to consume all the energy transferred to the representative volume. Thus all the energy delivered to the volume is absorbed (sunk) by the evaporation reaction. Mathematically the model is formulated as:

$$
\dot{\omega}_{e}=\left\{\begin{array}{cc}
\frac{j_{\text {Heat }}}{H_{e}} & T \geq T_{e} \text { and }<\rho_{L}>>0 \\
0 & \text { otherwise }
\end{array}\right.
$$

Where $\dot{\omega}_{e}$ is the evaporation rate, $T_{e}$ is the water boiling temperature, $H_{e}$ is the heat of water evaporation and $j_{\text {Heat }}$ is the heat flux towards to the representative volume. With the assumption that heat is not transferred by water, the heat flux is defined as:

$$
j_{\text {Heat }}=\nabla\left(\varepsilon_{G} u_{G}<\rho_{G}>^{G} C_{p, G}-\lambda_{e f f} \nabla T\right)
$$

The heat sink model of Lu et al. [65] assumes that the boiling temperature of water is fixed at 373 K. Nevertheless, strong local evaporation can cause noticeable changes in pressure which shifts the boiling temperature. The pressure effect on the boiling temperature can be modelled as [64]: 


$$
T_{e}=T_{e, 0} \log \left(\frac{<P_{G}>^{G}}{P_{0}}\right)+T_{0}
$$

545

546

547

548

549

550

551

552

553

554

555

556

557

558

559

560

561

562

563

564

565

566

567

568

569

570

571

572

573

574

Where $\left\langle P_{G}\right\rangle^{G}$ is the actual gas pressure, $P_{0}$ is atmospheric pressure (1atm), $T_{e, 0}$ is an empirical constant $(32.7 \mathrm{~K})$ and $T_{0}$ is the water boiling temperature at atmospheric pressure ( $\left.373 \mathrm{~K}\right)$.

The heat sink model describes the evaporation phenomena more accurately than the kinetic model, and it suits very well the models of large particles, which are subjected to a high temperature and a high heating rate. Nevertheless, it also has its flaws. The model assumes an infinitely thin moving volume where evaporation takes place, so it is not valid in case if the thickness of the drying volume is not negligible in comparison to the size of the domain [5]. Another disadvantage of the model is the application of a step function (Eq. (15.23)), which is hard to handle by a numerical solver and results in numerical instability $[57,66]$. The step function was investigated by Haberle et al. [64], who advised using an evaporation fraction factor $\left(f_{\text {evap }}\right)$ as the multiplier of the heat flux. The purpose of this limiting factor is to reduce the amount of the heat sunk by the evaporation reaction. In that way, the drying is distributed over neighbouring nodes, leading to the smoothing of the step and reduction of numerical instability. The disadvantage of such an approach is the forced broadening of the thickness of the drying volume.

\subsubsection{Equilibrium model}

The equilibrium model assumes that an equilibrium betweenliquid water and water vapour exists inside the particle's pores. The water vapour's partial pressure at any given time tends to be equal to the saturation vapour pressure (when the biomass moisture content is above the fibre suration point, or FSP) or saturation vapour pressure reduced by the relative humidity factor (moisture content below the FSP). For a whole range of moisture concentrations, it can be stated that:

$$
<P_{v}^{e q}>^{G}= \begin{cases}P_{\text {sat }}(T) & \left(M C>M C_{F S P}\right) \\ P_{\text {sat }}(T) \kappa\left(M C_{B}, T\right) & \left(M C \leq M C_{F S P}\right)\end{cases}
$$

Where $\left\langle P_{v}^{e q}\right\rangle^{G}$ is the equilibrium's partial pressure of water vapour, $P_{s a t}(T)$ is the saturation pressure in function of the temperature, $\kappa\left(M G_{B}, T\right)$ is the relative humidity factor calculated from the wood isotherm. This parameter depends on the bound water content and the temperature. The saturation pressure in function of temperature can be obtained from Raznjevic's [67] experimental correlation:

$$
P_{\text {sat }}=\exp \left(24.2101-\frac{467.3545}{T}\right)
$$

The equation for the wood's relative humidity can be obtained based on data from the Encyclopaedia of Wood (1980) [68], which was obtained by Grønli [52]:

$$
\kappa\left(M C_{B}, T\right)=1-\left(1-\frac{M C_{B}}{M C_{F S P}}\right)^{6.453 \cdot 10^{-3} T}
$$

From the equilibrium partial pressure, the vapour density can be obtained through:

$$
<\rho_{v}^{e q}>^{G}=\frac{<P_{v}^{e q}>^{G} M_{H_{2} O}}{R T}
$$

Where $\widehat{\mathrm{M}_{2} \mathrm{O}}$ is the molecular mass of water. Taking into account all above, the final equation for water evaporation rate can be defined as:

$$
\dot{\omega}_{e}=\frac{\varepsilon_{G}\left(<\rho_{v}^{e q}>^{G}-<\rho_{v}>^{G}\right)}{t_{e q}}
$$


Where $\left\langle\rho_{v}^{e q}\right\rangle^{G}$ is the equilibrium vapour density, $\left\langle\rho_{v}\right\rangle^{G}$ is the water vapour density at a given time and $t_{e q}$ is the time it takes to reach equilibrium between the actual vapour density and theoretically assumed saturation vapour density ("equilibration time"). Jahili et al. [54] stated that the equilibration time has to be appropriately short in relation to the pore diameter of wood and proposed a constant value of $10^{-5} \mathrm{~s}$. Lu et al. [65] proposed a correlation of the equilibration time based on particle specific surface area and pore diameter, expressed as:

$$
t_{e q}=S_{S S A} \frac{3.66 D_{\text {eff }, H_{2} O}}{d_{\text {pore }}}
$$

Where $S_{S S A}$ is the specific surface area of a porous particle, $D_{e f f, H_{2} O}$ is the effective diffusivity of water, calculated according to the work of Olek et al. [69] and $d_{\text {pore }}$ is the average pore diameter. In their work, Lu et al. applied values obtained experimentally from $\mathrm{N}_{2}$ adsorption [65].

The equilibrium model was designed initially for the modelling of slow,low-temperature drying. Nevertheless, it was also applied in the modelling of fast, high-temperature drying, but only with moderate success $[57,64,65,70,71]$. In the literature, hybrid evaporation models can also be found. Those models combine different models for liquid and bound water evaporation $[63,64]$.

\subsubsection{The heat of water evaporation}

The most convenient way to implement the heat of evaporation is by using a constant value. For models without differentiation between liquid and bound water or models with liquid water only, the heat of evaporation can be assumed to be equal to $2440 \mathrm{~kJ} / \mathrm{kg}$ (at $20^{\circ} \mathrm{C}$ ) $[64,65]$ or as 2257 $\mathrm{kJ} / \mathrm{kg}\left(\right.$ at $100^{\circ} \mathrm{C}$ ) [57]. A more appropriate way to implement the heat of evaporation can be done by using a temperature-dependent heat of evaporation correlation, e.g. the equation suggested by Ranzjevic [67]:

$$
H_{L}=3179-2.5 \mathrm{~T}
$$

Where $H_{L}$ is the heat of water evaporation. In models where both liquid and bound water are distinguished, a more complex approach for describing the heat of evaporation is needed. Such a model should include an additional term to account for the energy required for unbinding of the bound water prior to its evaporation. As such, the heat of evaporation for a whole range of moisture contents (liquid and bounded water) can be defined as:

$$
H_{e}=\left\{\begin{array}{l}
H_{L} \text { if } M C \geq M C_{F S P} \\
H_{L}+H_{B} \text { if } M C<M C_{F S P}
\end{array}\right.
$$

Where $H_{e}$ is the total evaporation heat of water and $H_{B}$ is the the energy needed to unbind the water. The latter can be calculated using the equation proposed by Stanish [72]:

$$
H_{B}=0.4 H_{L}\left(1-\frac{M C_{B}}{M C_{F S P}}\right)^{2}
$$

\subsubsection{Shape specification and coordinate systems}

The most common coordinate system for fluid dynamics is the Cartesian coordinate system. In cases where the particle anisotropy in a direction other than Cartesian's the implementation of another coordinate system can be beneficial. A wood particle does not have large property differences in the radial and tangential direction. Therefore in case of a wood particle, despite the particle's anisotropy, the Cartesian system can be applied without significant error. Table 15.2 
shows the changes in description between coordinate systems for particles of different shapes: block (Cartesian), cylinders (Cylindrical) and spheres (Polar).

Table. 15.2 Coordinate systems for CFD systems (D - number of dimensions).

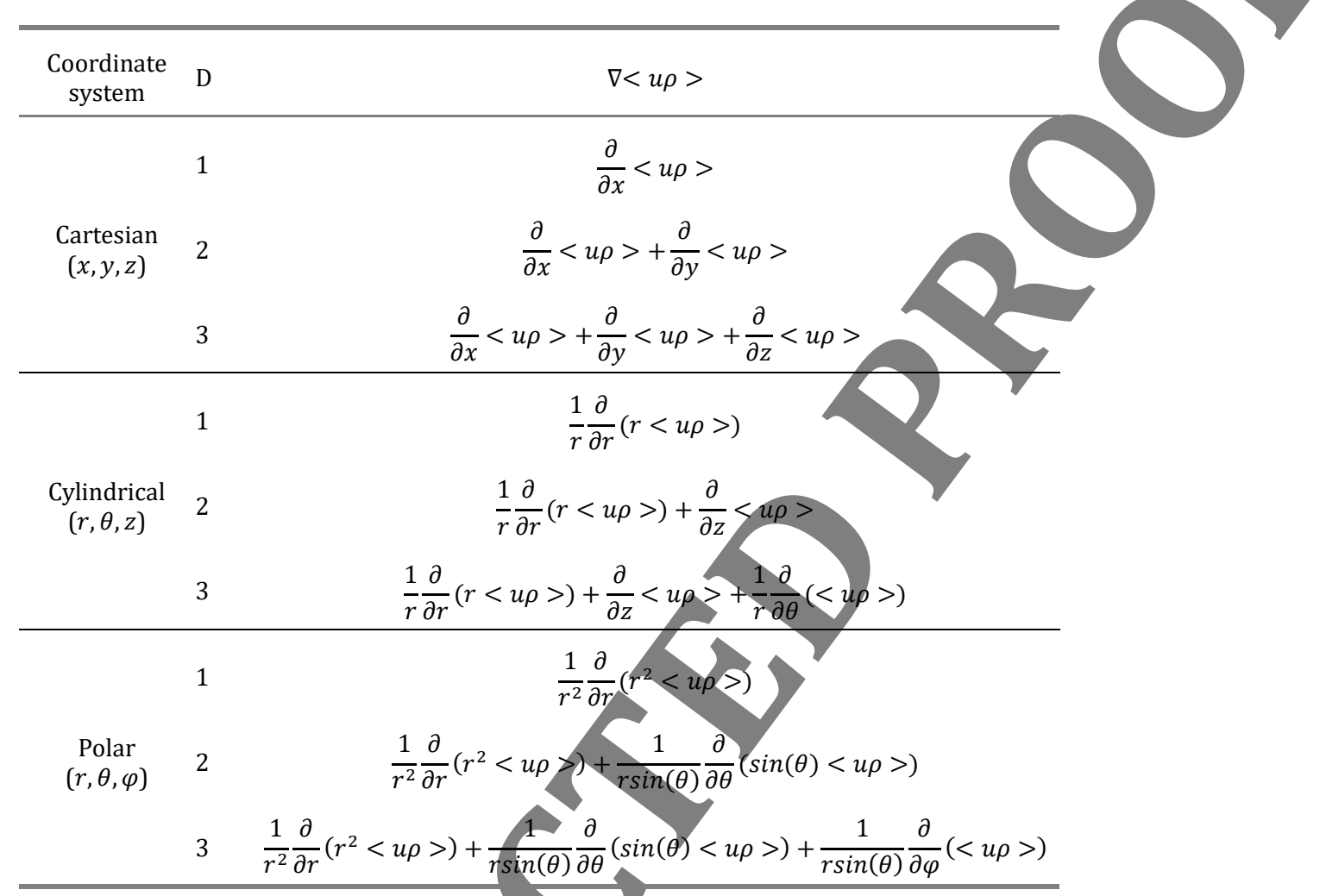

\subsubsection{Density}

\subsubsection{Density of biomass}

The composition and the structure of biomass differ significantly not only with plant species but also within individual specimens of the same species. Moreover, the climate, the availability of nutrients, solar radiation and genetic changes have an influence on the plant growth, hence its structure and composition, Also, different plant organs differ in structure and composition. This leads to significant differences in biomass densities among others. Analysis of apparent density (oven dry) data of 167 measurements of the Pinaceae family from the Global Wood Density Database shows a significant heterogeneity within one family of a single plant $(\mathrm{n}=167$, average $=$ $435 \mathrm{~kg} / \mathrm{m}^{3}$, st. dev. $=65 \mathrm{~kg} / \mathrm{m}^{3}$ ).

Measurement of the solid's apparent density can be conducted by a simple measurement of weight over mass. This is not a very accurate method, especially for finely ground biomass or char samples, due to the free spaces between the grains of a solid. A more sophisticated method for measuring the apparent density is mercury porosimetry, in which $\mathrm{Hg}$ displaces gas around the grain. At atmospheric pressure, mercury is not able to penetrate pores whose size is below $15 \mu \mathrm{m}$. Therefore, the result of the measurement by mercury porosimetry is only slightly overestimated [52]. Due to the high toxicity of mercury, recently more interest is devoted to measurement methods with micro-granular suspensions. Their role is similar to mercury and relies on displacement of the gas from spaces between the grains. Some sources call the density measured 
with micro-granular suspensions as "envelope" density [73], in order to distinguish it from bulk

635 density, but stay with the name "apparent" [74].

The true (skeletal, intrinsic) density is measured by helium pycnometry. The method uses helium as the pore displacement gas because it can penetrate pores with a diameter larger than $40 \mathrm{~nm}$ [52]. If the analysed material does not have closed pores, helium pycnometry allows for very accurate true density measurements. As is shown in the work by Brewer et al. [75], some pores in the biochar structure are not penetrable by helium, without prior grinding of the material.

Knowing both true and apparent densities and in case that samples were measured with zero moisture (dry state), the volume fraction occupied by gas, can be calculated using:

$$
\varepsilon_{G}=1-\varepsilon_{S}
$$

The orientation of the cut plane of a sample during true density measurement influences the result due to the anisotropy within the wood cell walls. Table 15.3 shows a summary of the apparent and true densities together with resulting porosity for selected biomasses. If not specified, the sample anisotropy was not taken into account in the measurement. Hardwood, TW-Tropical wood, GR- Grass, (L)-Longitudinal, (T)-Transverse)

\begin{tabular}{|c|c|c|c|c|c|}
\hline $\begin{array}{c}\text { Species } \\
\text { (Common name) }\end{array}$ & Type & $\begin{array}{c}\text { Apparent } \\
\text { density }\end{array}$ & & & Ref. \\
\hline$[-]$ & {$[-]$} & {$\left[\mathrm{kg} / \mathrm{m}^{3}\right]$} & $\left.\mathrm{kg} / \mathrm{m}^{3}\right]$ & {$[-]$} & {$[-]$} \\
\hline Birch & $\mathrm{HW}$ & 580 & 1450 & 0.600 & \multirow{2}{*}{ [52] } \\
\hline Spruce & sW & 17 & 1390 & 0.662 & \\
\hline Bilinga & TW & & 1458 & 0.586 & \multirow{20}{*}{ [74] } \\
\hline Beech & $\mathrm{HW}$ & & 1472 & 0.469 & \\
\hline Boxwood & & & 1506 & 0.376 & \\
\hline Danta & & & 1480 & 0.528 & \\
\hline Afzelia & & & 1501 & 0.450 & \\
\hline Yew & & & 1481 & 0.577 & \\
\hline & & 483 & 1512 & 0.681 & \\
\hline & & 401 & 1524 & 0.737 & \\
\hline & TW & 616 & 1501 & 0.590 & \\
\hline & $\mathrm{HW}$ & 594 & 1502 & 0.605 & \\
\hline & sw & 588 & 1481 & 0.603 & \\
\hline & TW & 625 & 1466 & 0.574 & \\
\hline Mêrbau & TW & 902 & 1518 & 0.406 & \\
\hline & TW & 426 & 1473 & 0.711 & \\
\hline Ramin & TW & 608 & 1505 & 0.596 & \\
\hline Black locust & HW & 726 & 1509 & 0.519 & \\
\hline Oak & $\mathrm{HW}$ & 706 & 1528 & 0.538 & \\
\hline Pine & sw & 451 & 1489 & 0.697 & \\
\hline White alder & HW & 538 & 1492 & 0.639 & \\
\hline White lauan & TW & 627 & 1474 & 0.575 & \\
\hline \multirow{2}{*}{ Spruce $(2 \mathrm{~mm})$} & \multirow{2}{*}{ sw } & \multirow{2}{*}{420} & 1470 (L) & 0.714 & \multirow{3}{*}{ [76] } \\
\hline & & & $1290(\mathrm{~T})$ & 0.674 & \\
\hline Spruce $(6 \mathrm{~mm})$ & SW & 420 & 1380 (L) & 0.696 & \\
\hline
\end{tabular}




\begin{tabular}{ccccc} 
& & & $1310(\mathrm{~T})$ & 0.679 \\
Maple $(2 \mathrm{~mm})$ & HW & 520 & $1510(\mathrm{~L})$ & 0.656 \\
& & & $1430(\mathrm{~T})$ & 0.636 \\
Maple $(6 \mathrm{~mm})$ & HW & 520 & $1430(\mathrm{~L})$ & 0.636 \\
& & & $1400(\mathrm{~T})$ & 0.629 \\
Ash wood (2 mm) & SW & 660 & $1360(\mathrm{~L})$ & 0.515 \\
& & & $1350(\mathrm{~T})$ & 0.511 \\
Ash wood (6 mm) & SW & 660 & $1320(\mathrm{~L})$ & 0.500 \\
\hline Mesquite wood & SW & n.a. & $1330(\mathrm{~T})$ & 0.504 \\
Miscanthus & GR & n.a. & 13204 & - \\
\hline
\end{tabular}

653 The char's density and porosity depend on the initial composition and structure of biomass, as 654 well as on the conditions of a pyrolysis process. The production temperature has a significant 655 effect on the char's true density, as opposed to the heating rate, which seems to not have a relevant 656 influence [75,77]. In Table 15.4 data of the true and apparent (if available) density as well as the 657 porosity of chars obtained from different biomasses distinguished by pyrolysis conditions is 658 summarised. The theoretical maximum of the true density of a char is $2250 \mathrm{~kg} / \mathrm{m}^{3}$, which refers 659 to the true density of graphite [78], but in practice, the maximum that can be obtained is within 660 661 the range between $2000 \mathrm{~kg} / \mathrm{m}^{3}$ and $2100 \mathrm{~kg} / \mathrm{m}^{3}$.

Table 15.4. True and apparent (if available) densities with resulting porosity of chars obtained from different biomasses.

\begin{tabular}{|c|c|c|c|c|c|c|}
\hline Species & $\begin{array}{c}\text { Final Pyro. } \\
\text { Temp. }\end{array}$ & & $\begin{array}{l}\text { Apparent } \\
\text { density }\end{array}$ & $\begin{array}{c}\text { True } \\
\text { density }\end{array}$ & Porosity & Ref. \\
\hline$[-]$ & & $/ \mathrm{min}$ & {$\left[\mathrm{kg} / \mathrm{m}^{3}\right]$} & {$\left[\mathrm{kg} / \mathrm{m}^{3}\right]$} & {$[-]$} & {$[-]$} \\
\hline Birch & 000 & 5.0 & 390 & 1570 & 0.752 & \multirow{2}{*}{ [52] } \\
\hline Spruce & & 5.0 & 390 & 1540 & 0.747 & \\
\hline & & \multirow{7}{*}{5.0} & 603 & 1340 & 0.550 & \multirow{16}{*}{ [75] } \\
\hline & & & 532 & 1382 & 0.615 & \\
\hline & & & 523 & 1384 & 0.622 & \\
\hline & 450 & & 476 & 1433 & 0.668 & \\
\hline & 500 & & 492 & 1520 & 0.676 & \\
\hline & 600 & & 447 & 1634 & 0.726 & \\
\hline & 700 & & 509 & 1735 & 0.707 & \\
\hline & 350 & \multirow{6}{*}{5.0} & 262 & 1392 & 0.812 & \\
\hline & 400 & & 282 & 1438 & 0.804 & \\
\hline & 450 & & 274 & 1466 & 0.813 & \\
\hline Miscantnus & 550 & & 286 & 1611 & 0.822 & \\
\hline & 600 & & 293 & 1722 & 0.830 & \\
\hline & 700 & & 271 & 1965 & 0.862 & \\
\hline \multirow{3}{*}{ Miscanthus } & 350 & 23.3 & 284 & 1357 & 0.791 & \\
\hline & 360 & 24.0 & 307 & 1368 & 0.776 & \\
\hline & 370 & 24.7 & 271 & 1380 & 0.804 & \\
\hline
\end{tabular}




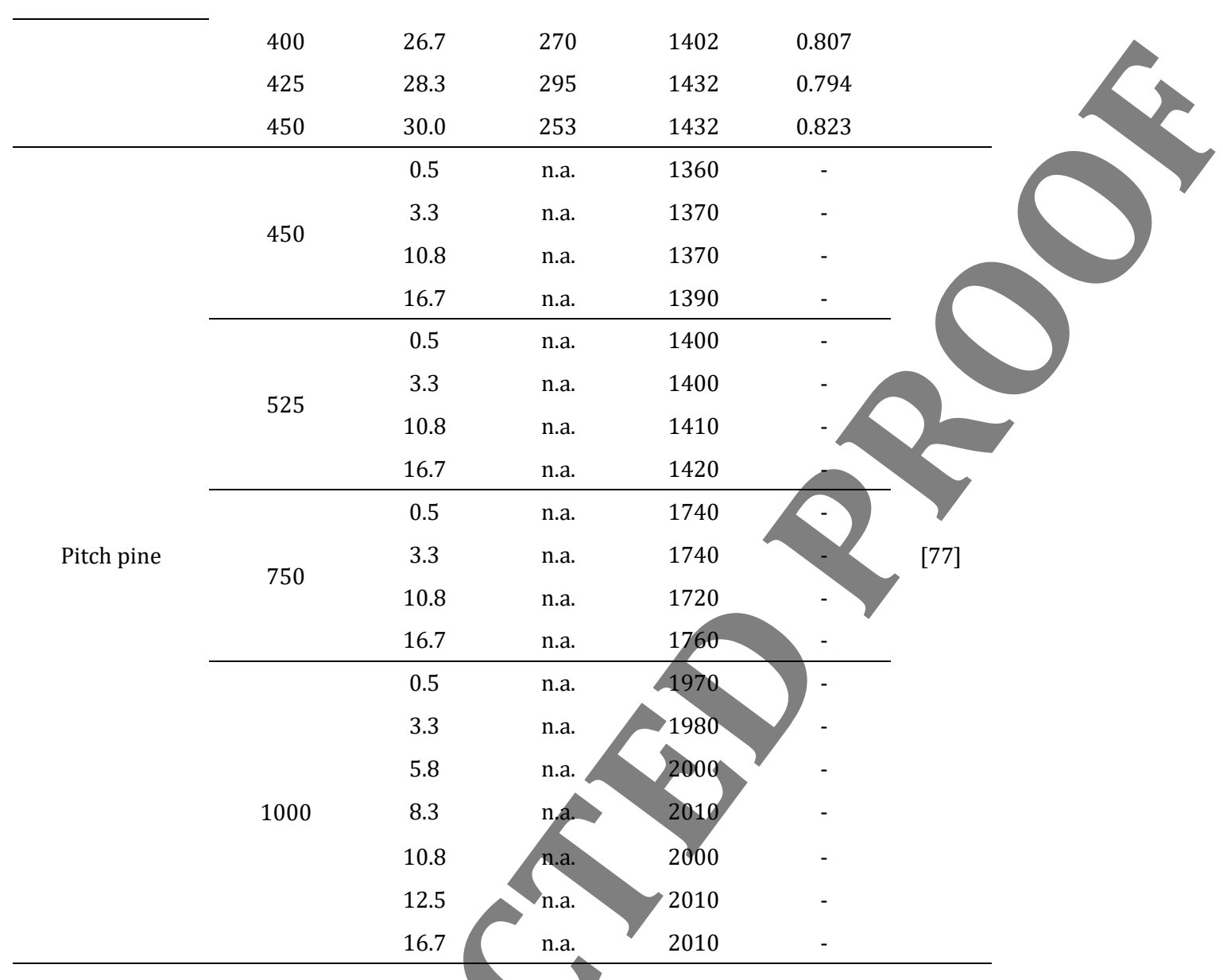

\subsubsection{Densities of bound and liquid water}

666 Bound water is water that exists in the biomass structure, and which is partially incorporated into the cell wall. In literature an explanation of the interaction between bound water and the cell structure as well as information about the storage locations of bounded water can be found [79]. In general, the cell wall of biomass, due to its chemical structure, is hydrophilic in its nature, and it has the ability to interact with water molecules through hydrogen bonding. Through this mechanism, water is able to stick to the wall and occupy empty spaces in its structure [80].

The cells wall of biomass has only a finite ability to bind water. To describe the amount of water that can be bound to a wall, the term fibre saturation point (FSP) was introduced first by Tiemann in 1906 [79]. It is defined as the moisture content below which only bound water exists in a biomass structure. Above the fibre saturation point, cell walls cannot bind more water, so both bound and liquid water can exist. In literature, the two most commonly applied values of the base FSP have been reported. 30\% proposed by Stamm in 1971 [81] and 40\% proposed by Skaar in 1988 [82]. Measurements show that above the FSP, the density of the bound water is close to 1110 $\mathrm{kg} / \mathrm{m}^{3}$ and with moisture content close to zero its value rises up to $1300 \mathrm{~kg} / \mathrm{m}^{3}$ [83]. The bound water's density increases at lower moisture content, according to the cell wall binding strength peramount of available water molecules [80]. In order to avoid over-complexity of the problem, authors typically use a constant value of $1000 \mathrm{~kg} / \mathrm{m}^{3}$ for the true density of the bound water $[52,54,57,64,65]$.

The true density of the liquid water depends on the temperature, due to its thermal expansion. In the pyrolysis conditions, the water does not significantly exceed $100{ }^{\circ} \mathrm{C}$, so the simplification that the true density of water has a constant value of $1000 \mathrm{~kg} / \mathrm{m}^{3}$ does not induce strong inaccuracies in the model. 
689

690

691 692

694 695

696

697

698

699

700

701

702

703

704

705

706

707

708

709

Temperatures and intrinsic pressures during pyrolysis allow for the assumption that gases and vapours can be treated as ideal gases, so:

$$
<P_{i}>^{G}=\frac{<\rho_{i}>^{G} R T}{M_{i}}
$$

Where $\left\langle P_{i}\right\rangle^{G}$ and $M_{i}$ are the partial pressure and molar mass of $i^{\text {th }}$ component in the gas mixture, respectively. The total gas density can be calculated from:

$$
<\rho_{G}>^{G}=\sum_{i}^{N}<\rho_{i}>^{G}
$$

The molecular mass of the gas mixture is defined as:

$$
M_{G}=\left(\sum_{i}^{N} \frac{<\rho_{i}>^{G}}{<\rho_{G}>^{G} M_{i}}\right)^{-1}
$$

$15.37)$

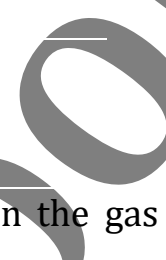

Where $M_{G}$ is the mean molar mass of the gas mixture. The total gas pressure can be calculated as:

$$
<P_{G}>^{G}=\frac{<\rho_{G}>^{G} R T}{M_{G}}
$$

Where $\left\langle P_{G}\right\rangle^{G}$ is the total pressure. In case of the application of a simple, single-component model, permanent gases and tars are often treated not as a product mixture, but as single representative species of the mixture. For example in the work of Grønli [52], tars are represented by benzene with a molecular mass of $110 \mathrm{~g} / \mathrm{mol}$ and gases are represented by a 1:1 mixture of carbon monoxide and carbon dioxide with a molecular mass of $38 \mathrm{~g} / \mathrm{mol}$.

\subsubsection{Moisture content and saturation}

The amount of water in biomass is described by the moisture content (MC), and calculated as:

$$
M C=\frac{\text { mass of water }}{\text { mass of biomass }(\mathrm{db} .)}
$$

The water in biomass can exist in two phases, so:

$$
M C=M C_{L}+M C_{B}
$$

Where $M C_{L}$ is the moistare related to the liquid water and $M C_{B}$ is the moisture related to the bound water. To calculate both moisture contents, the value of the fibre saturation point (function of the temperate) has to be obtained, for example, with the equation proposed by Siau [84]:

$$
M C_{F S P}(T)=\left(M_{F S P}^{o}+0.298\right)-0.001 T
$$

Where $M C_{F S P}$ is the fibre saturation point at a certain temperature, and $M_{F S P}^{o}$ is the base fibre saturation point (value between 0.3 or 0.4 ). Knowing that only above the fibre saturation point both types of water can be found in biomass, it can be stated that:

$$
\begin{gathered}
M C_{B}=\min \left(M C_{F S P}, M C\right) \\
M C_{L}=\max \left(M C-M C_{F S P}, 0\right)
\end{gathered}
$$


With the assumption that the water content in the gas phase is negligible, the apparent density of 711 bound and liquid water can be calculated respectively:

$$
\begin{gathered}
M C_{B}=\frac{<\rho_{B}>}{<\rho_{S}>} \\
M C_{L}=\frac{<\rho_{L}>}{<\rho_{S}>}
\end{gathered}
$$

712

713

714

715

716

Where $\left\langle\rho_{S}\right\rangle$ is the solid's apparent density in the dry state. Having the value of the true and apparent density for both water types, the volume fraction occupied by these phases can be calculated.

Saturation of a particle quantifies to what extent the space within pores is occupied by water. This value should not be confused with the $M C_{F S P}$. Saturation is defined as?

$$
S=\frac{\text { liquid volume }}{\text { pore volume }}
$$

Where pore volume is a particle's empty (filled with gas) volume which theoretically can be occupied by the liquid water. When equal representative volumes are considered:

$$
S=\frac{M C_{L}}{M C_{s a t}-M_{F S P}}
$$

Where $M C_{\text {sat }}$ is the maximum moisture content which can be retained by a biomass structure:

$$
M C_{\text {sat }}=M C_{F S P}+M C_{s a t, L}
$$

Where $M C_{s a t, L}$ is the maximum liquid water content which can be retained by a biomass structure. Assuming that during the maximum saturation state all pores of biomass are filled with water, and that liquid and bound water have the same density, $M C_{\text {sat }}$ can be obtained from the equation:

$$
M C_{\text {sat }}=<\rho_{L}>^{L}\left(\frac{1}{<\rho_{S}>}-\frac{1}{\left.<\rho_{S}\right\rangle^{S}}\right)
$$

In the literate devoted to wood drying, a parameter "irreducible water content of structure" $\left(S_{\text {irr }}\right)$ can be found. It refers to the water bound so strongly to a cell wall structure that it is not removed during a conventional drying processes (up to $120^{\circ} \mathrm{C}$ ). In the model of a pyrolysis process of biomass, it is not advisable to implement such parameter for two reasons. First, the energy flux added to water is much higher than in conventional drying due to higher temperatures. Theoretically, it should allow for complete unbinding of water. Second, even if the energy flux would be insufficient during the pyrolysis, the structure of biomass changes and cell walls lose their binding ability (hydrophilicity).

\subsubsection{Capillary pressure}

For models in which the transportation term for the liquid water is included in the mass conservation equation, the capillary pressure needs to be defined. Capillary pressure in the lumens of wood is defined as:

$$
<P_{L}>^{L}=<P_{G}>^{G}+P_{C}
$$

Where $P_{C}$ is a capillary pressure and $\left\langle P_{L}\right\rangle^{L}$ is pressure in of the liquid water. In literature different correlations for the capillary pressure can be found. An extensive comparison can be found in the work of Jalili et al. [54]. Here are shown only two, most commonly used empirical correlations, one by Spolek and Plumb [85]: 


$$
P_{C}=\frac{8.4 \cdot 10^{4}}{S^{0.63}}
$$

739 Where $S$ is the saturation. The second, by Perre and Degiovanni [86]:

$$
P_{C}=\frac{1.364 \cdot 10^{5} \sigma(T)}{\left(M C_{L}+1.2 \cdot 10^{-4}\right)^{0.63}}
$$

Where $\sigma(T)$ is the temperature-related coefficient, defined as:

$$
\sigma(T)=(128-0.185 T) \cdot 10^{-3}
$$

Both above mentioned empirical correlations were established for softwood. Therefore they should be applied only for modelling those biomasses due to significant differences in pore size, pore shape and surface wettability with other wood types.

\subsubsection{Permeability}

The permeability has a major influence on the fluid movement through a porous structure. The permeability determines the superficial velocity and pressure formation of gases and transport of liquid water in a porous biomass structure.

\subsubsection{Intrinsic permeability of biomass}

The proper assumption regarding biomass permeability is not an easy task. As it was pointed out by Grønli [52], the value of the intrinsic gas permeability of wood shows high variability and strongly depends on:

- type of wood: hardwood or softwood

- position in the plant from which the wood sample was taken: heartwood (older part) or sapwood (younger part)

- cut plane direction (related to sample anisotropy): longitudinal, tangential or radial

Table 15.5 contains experimental data of the intrinsic gas permeability of selected biomasses. As it can be noticed, sapwoods show higher intrinsic gas permeability than heartwoods. Regarding the cut plane direction, the permeability in the longitudinal direction is much higher than in the radial or tangential direction, for which values are comparable. Taking this into account, the assumption that radial and tangential permeability are equal does not lead to a significant loss in model accuracy. In publications related to modelling, the implemented values of the intrinsic gas permeability sometimes differ significantly from those experimentally obtained. For example, some authors adjust the permeability values according to the simulation's result, or, as it was done by Di Blasi [71], the author adapted permeability to obtain the same pressure as in the experimental data from Lee et al. [87].

\begin{tabular}{|c|c|c|c|c|c|c|c|c|}
\hline \multirow{3}{*}{ Species } & \multirow{3}{*}{$\mathrm{P}$} & \multicolumn{3}{|c|}{ Permeability } & \multicolumn{3}{|c|}{ Ratio } & \multirow{3}{*}{ Ref. } \\
\hline & & \multicolumn{3}{|c|}{$\left[\mathrm{m}^{2}\right]$} & \multicolumn{3}{|c|}{$[-]$} & \\
\hline & & $\mathrm{L}$ & $\mathrm{R}$ & $\mathrm{T}$ & $\mathrm{L} / \mathrm{R}$ & $\mathrm{R} / \mathrm{T}$ & $\mathrm{L} / \mathrm{T}$ & \\
\hline Pine & $\mathrm{h}$ & $2.98 \mathrm{E}-11$ & $2.07 \mathrm{E}-15$ & $3.65 \mathrm{E}-16$ & 14381 & 5.68 & 81621 & \\
\hline Pine & $\mathrm{h}$ & $1.86 \mathrm{E}-12$ & $3.55 \mathrm{E}-16$ & $7.80 \mathrm{E}-17$ & 5222 & 4.56 & 23797 & [88] \\
\hline Fir & $\mathrm{s}$ & $8.88 \mathrm{E}-13$ & $7.90 \mathrm{E}-17$ & $1.28 \mathrm{E}-17$ & 11250 & 6.15 & 69230 & \\
\hline
\end{tabular}

Table 15.5 Intrinsic gas permeability for selected biomass in different directions ( $\mathrm{P}$ - place in the wood, s- sapwood, $\mathrm{h}$ heartwood, L - longitudinal, T - tangential, R - radial, n.a. - not available) 


\begin{tabular}{cccccccc} 
Fir & $\mathrm{h}$ & $4.44 \mathrm{E}-14$ & $1.51 \mathrm{E}-17$ & $1.68 \mathrm{E}-18$ & 2941 & 9.00 & 26470 \\
Douglas-fir & $\mathrm{h}$ & $1.78 \mathrm{E}-14$ & $5.43 \mathrm{E}-19$ & $1.48 \mathrm{E}-18$ & 32727 & 0.37 & 12000 \\
& & & & & & & \\
Redwood & $\mathrm{s}$ & $1.40 \mathrm{E}-11$ & $3.95 \mathrm{E}-16$ & $1.23 \mathrm{E}-14$ & 35500 & 0.03 & 1136 \\
Redwood & $\mathrm{h}$ & $5.38 \mathrm{E}-12$ & $3.95 \mathrm{E}-16$ & $5.92 \mathrm{E}-16$ & 13625 & 0.67 & 9083 \\
Red cedar & $\mathrm{s}$ & $1.63 \mathrm{E}-12$ & $1.97 \mathrm{E}-16$ & $1.97 \mathrm{E}-15$ & 8250 & 0.10 & 825 \\
Red cedar & $\mathrm{h}$ & $1.04 \mathrm{E}-12$ & $1.38 \mathrm{E}-15$ & $1.97 \mathrm{E}-15$ & 750 & 0.70 & 525 \\
\hline Spruce & $\mathrm{s}$ & $1.90 \mathrm{E}-16$ & $2.90 \mathrm{E}-18$ & n.a. & 65.52 & n.a. & n.a. \\
Maritime & $\mathrm{s}$ & $1.47 \mathrm{E}-17$ & $8.60 \mathrm{E}-16$ & n.a. & 0.02 & n.a. & n.a. \\
pine & & & & & & & \\
Scots pine & $\mathrm{s}$ & $7.10 \mathrm{E}-16$ & $4.20 \mathrm{E}-17$ & n.a. & 16.90 & n.a. & n.a. \\
\hline
\end{tabular}

Analysis of the intrinsic gas permeability with differentiation on the cut plane direction, for c.a. 100 different wood samples was made by Smith and Lee in 1958 [84]. Results of their study are presented in Fig. 15.6. Values of the longitudinal permeability used by modellers are in general within the range of experimental data, but for the radial permeability, values are usually overstated by at least one order of magnitude [50,71,90-93]. From experimental data, it can be stated that the valid range for the longitudinal intrinsic gas permeability is between $10^{-11} \mathrm{~m}^{2}$ and $10^{-17} \mathrm{~m}^{2}$ and for the radial between $10^{-15} \mathrm{~m}^{2}$ and $10^{-19} \mathrm{~m}^{2}$.

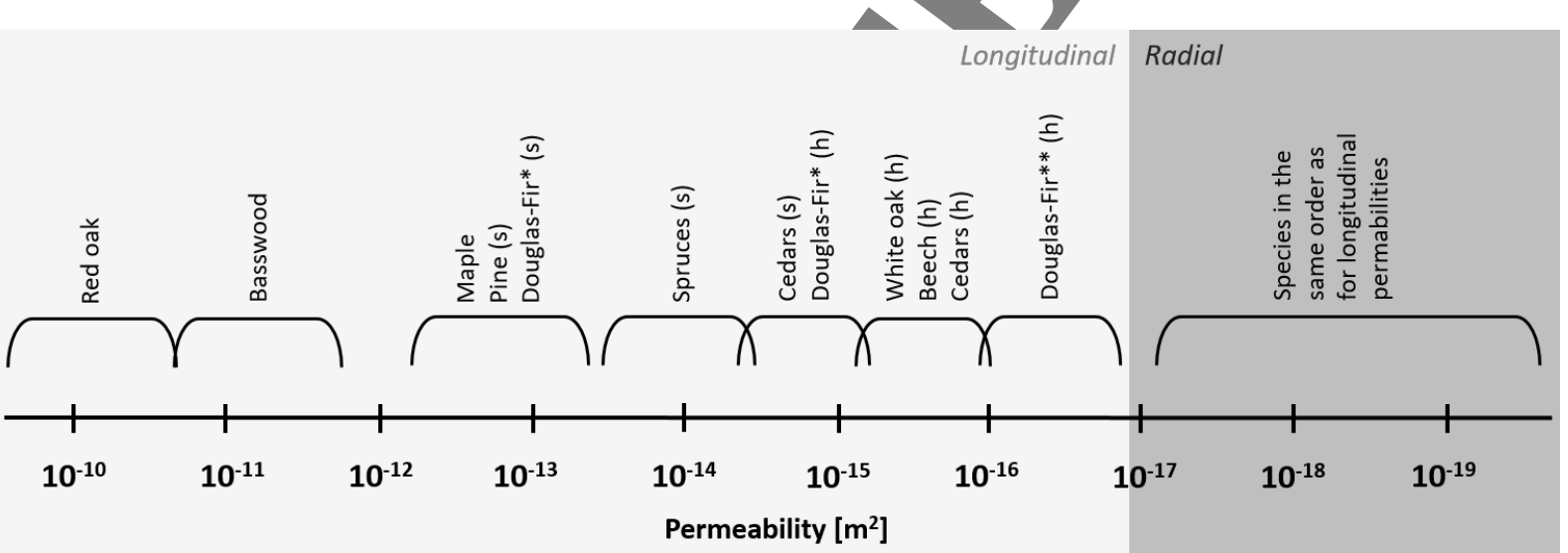

Figure 15.6 Intrinsic gas permeability range for woods, based on the data from Smith and Lee [84]. (s-sapwood, h-heartwood, $*$ - sample from the coast, ${ }^{* *}$ - sample from mountains)

\subsubsection{Intrinsic permeability of char}

The thermal decomposition of biomass increases the internal volume of the structure. Therefore, chars formed in pyrolysis show higher permeability than the initial biomass due to an increase of the size of the channels (pore size) and development of new pores and cracks in the cell walls. Experimentally measured permeabilities of char are rarely found in the literature. Hence, most works related to the modelling of biomass pyrolysis estimate its value. Usually, the permeability of a char in the longitudinal direction is estimated to be about 1-2 orders of magnitude higher, and in the radial and tangential direction from 1 to 4-5 orders of magnitude higher than a value of the initial biomass. In Table 15.6 data of the intrinsic permeability of a pinewood char is presented. Unfortunately, the data source did not provide information regarding the direction other than the longitudinal.

Table 15.6 Pinewood char's longitudinal intrinsic gas permeability as a function of pyrolysis temperature [94]

$$
\text { Temperature Permeability Raw/Char }
$$




\begin{tabular}{ccc}
{$\left[{ }^{\circ} \mathrm{C}\right]$} & {$\left[\mathrm{m}^{2}\right]$} & {$[-]$} \\
\hline 20 & $5.42 \mathrm{E}-13$ & - \\
200 & $9.27 \mathrm{E}-13$ & 1.71 \\
250 & $1.20 \mathrm{E}-12$ & 2.22 \\
300 & $2.68 \mathrm{E}-12$ & 4.94 \\
350 & $5.74 \mathrm{E}-12$ & 10.58 \\
\hline
\end{tabular}

\subsubsection{Intrinsic permeability of liquid water}

799

800

801

802

803

804

805

806

Table 15.7 shows a summary of the relationship between the intrinsic permeability of a gas and liquid water in biomass. According to the literature, the liquid permeability should be in the range of $+/-1$ order of magnitude different than that of the gas permeability. It is worth to mention that during pyrolysis at any given time, the liquid water does not co-exist with the char.

Table 15.7 Relationship between gas and liquid intrinsic permeability in biomass

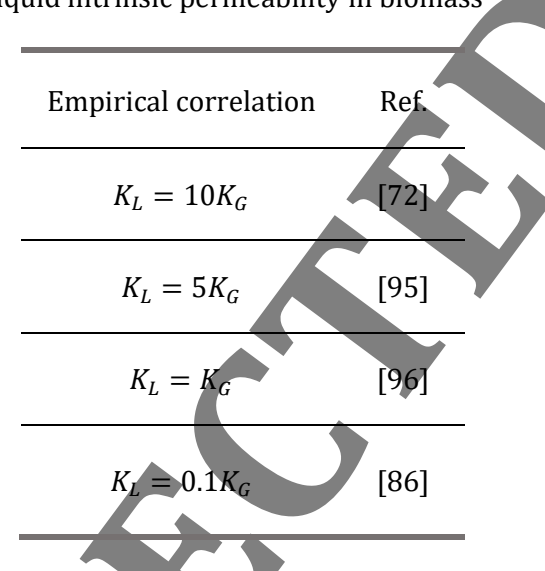

\subsubsection{Intrinsic, relative and effective permeability}

The intrinsic permeability at any time of the reaction is defined as:

$$
K_{p h}=X_{B M} K_{p h, B M}+X_{B C} K_{p h, B C}
$$

Where $K_{p h}$ is the intrinsic permeability of a phase and $X_{B M}$ and $X_{B C}$ are the mass ratio of the unreacted biomass and biochar in the solid matrix, respectively. The subscript $p h$ refers to a particular phase (gas or liquid).

The relative permeability reflects the difference between a material effective permeability in a wet state and the intrinsic permeability in a dry state. The correlation of moisture content and the permeability is expressed by the saturation. The most commonly used correlation is the one developed by Perre et al. [97] and is shown in Table 15.8. It is based on experimental data retrieved on softwood. In literature, other correlations between saturation and relative permeability are also available [54].

Table 15.8 Most commonly used correlations for relative gas and liquid permeabilities [96].

Relative permeability

Direction

$$
\text { Gas }\left(K_{G, r e l}\right) \quad \text { Liquid }\left(K_{L, r e l}\right)
$$




\begin{tabular}{ccc}
\hline Longitudinal & $1+(4 S-5) S^{5}$ & $S^{8}$ \\
Tangential & $1+(2 S-3) S^{2}$ & $S^{3}$ \\
\hline
\end{tabular}

821

822

823

824

825

826

827

828

829

830

831

832

833

834

835

836

837

838

839

840

841

The effective permeability consists of two parts: a first related to the solid porous structure (intrinsic permeability) and a second related to the effect of saturation of pores on the fluid movement (relative permeability). Effective permeability can be calculated as:

$$
K_{p h, e f f}=K_{p h} \cdot K_{p h, r e l}
$$

Where $K_{p h, e f f}$ is the effective permeability of a phase, $K_{p h}$ is the intrinsic permeability of a phase, and $K_{p h, r e l}$ is the relative permeability of a phase.

\subsubsection{Diffusion}

\subsubsection{Bound water diffusion}

The migration of bound water arises only from diffusion through cell walls of biomass. Mathematically, such transport can be described using Fick's law [98]. During pyrolysis and at any given time, bound water does not co-exist with biochar.

By fitting the experimental data of bound water diffusivity in a transverse direction, the following correlations based on the Arrhenius expression were proposed:

Perre and Degiovanni [86]:

$$
D_{B, T}=\exp \left(-9.9+9.8 M C_{B}-\frac{4300}{T}\right)
$$

Perre and Turner [98]:

$$
D_{B, T}=\exp \left(-12.818+10.895 M C_{B}-\frac{4300}{T}\right)
$$

Stamm [99] stated that the following dependency exists between diffusion of bound water in different directions:

$$
D_{B, T} \cong \frac{1}{3} D_{B, L} \cong \frac{2}{3} D_{B, R}
$$

Where subscripts T, L, and R denote the transverse, longitudinal and radial direction respectively. More complex dependency between bound water diffusion and direction can be found in the works of Pierre and Turner $[98,100]$.

\subsubsection{Gas binary diffusion}

The gas-vapour mixture, which exists in the pores during pyrolysis consists of a variety of compounds in different concentrations and its composition changes as the process progresses. Mathematical description of such a process is not straightforward.

Application of binary diffusion description is valid only for systems where only two major components interact with each other, and there are no other components or their influence on a mixture is negligible. Also, binary diffusion is based on the assumption that one compound has to be indicated as an inert during the whole process. Such a situation is far different from the one that takes place in the pores during the pyrolysis process of biomass. Therefore, the application 
of the binary diffusion description can lead to significant inaccuracies in prediction. Hence, other more complex ways of describing diffusion have to be applied. A satisfactory procedure which is always valid for a multi-component system is the Maxwell-Stefan equations system, so in theory, its application would be the most valid option [101].

Diffusion is the dominating transport phenomenon only in systems where large pressure gradients do not exist. An increase in the pressure gradient leads to a reduction of the diffusion's share in the overall transport of gases, as convection becomes the dominating phenomenon of transport [52]. During pyrolysis of dry biomass, especially at high temperatures and with a high heating rate, the pressure gradients are significant, which indicates that the diffusion does not play a major role in gas transport. It leads to the conclusion that implementation of the binary diffusion model, which will be rather inaccurate, but fairly simple in implementation and easy in computation should not add a significant inaccuracy to the prediction of fast pyrolysis. In general, it is always advised to try to avoid the application of a robust, global description, which can be overcomplex and simultaneously not lead to visible improvement in modelling accuracy.

On the other hand, for a pyrolysis process of wet biomass, so combined with particle's drying, the diffusion of water vapour can be significant. Especially for pyrolysis of a large particle that is exposed to moderate thermal conditions, where evolved pressure gradients can be insufficient to shift the convection into the dominant transport process. For such situations, an assumption that diffusion is negligible will not be valid. During drying, an inert (most often nitrogen) - water vapour system will appear, which can be described satisfactorily by binary diffusion. Often in practice, the binary diffusion of an inert-water vapour system is treated as an air-water vapour system instead of nitrogen-water vapour system due to the marginal difference in gas properties and higher availability of data for the air-water vapour system.

The air-water vapour binary diffusion coefficient $\left(D_{A / V}\right)$, in function of the temperature and the pressure inside a particle, can be calculated with the equation proposed by Siau [84]:

$$
D_{A / V}=2.23 \cdot 10^{-5} \frac{T^{1.81}}{\left.<P_{G}\right\rangle^{G}}
$$

Alternatively, it can be calculated with a more often used equation, proposed by Grønli [52]:

$$
D_{A / V}=1.192 \cdot 10^{-4} \frac{T^{1.75}}{<P_{G}>^{G}}
$$

Correlations above can be used not only for the water vapour but also for other compounds in the pyrolysis gas mixture without introduction of a significant error. If higher accuracy is needed, a discrete description of the binary diffusion coefficient for each component of a system can be calculated with the Chapman-Enskog equation, based on the kinetic gas theory, or with the equation proposed by Poling et al. [102]:

$$
D_{\text {inert } / i}=1.43 \cdot 10^{-7} \frac{T^{1.75}}{P M_{\text {inert } / i}{ }^{1 / 2}\left[\left(\sum_{v}^{\text {inert }}\right)^{1 / 3}+\left(\Sigma_{v}^{i}\right)^{1 / 3}\right]^{2}}
$$

Where $D_{\text {inert } / j}$ is the binary diffusion coefficient between an inert and an $i^{\text {th }}$ component, $\Sigma_{v}$ is the sum of the atomic diffusion volumes (from Poling et al. [102]) and $M_{\text {inert } / i}$ is the mean molecular mass ratio between an inert and an $i^{\text {th }}$ compound.

The diffusion phenomena are omitted in certain publications related to modelling of pyrolysis of dry biomass $[28,42,56,103]$. Authors who modelled the pyrolysis of wet biomass have treated the diffusion coefficients as constant values (range from $10^{-6} \mathrm{~m}^{2} / \mathrm{s}$ to $10^{-5} \mathrm{~m}^{2} / \mathrm{s}$ ) for all gas species in order not to overcomplicate the model $[59,91,92,104]$. Such approaches are not fully invalid with respect to the minor role of diffusion in the overall transport of gases in specific cases. 
891

892

893

894

895

896

897

898

899

900

901

902

903

904

905

906

907

908

909

910

911

912

913

Besides the gas mixture composition, the structure of the porous material in which the diffusion process takes place has an influence on the diffusion coefficient. The effective gas diffusion coefficient can be defined as:

$$
D_{\text {eff, } \text { inert } / i}=\theta D_{\text {inert } / i}
$$

Where $D_{\text {eff } f \text {, inert } / i}$ is the effective inert - $i^{\text {th }}$ component diffusion coefficient, $D_{\text {inert } / i}$ is the inert $i^{\text {th }}$ component diffusion coefficient and $\theta$ is the structure resistance factor (tortuosity factor). The structure resistance factor is an artificial parameter describing the restriction of diffusion in narrow pores, which can be linked to the porosity. The correlation of the structure resistance factor to porosity is obtained by fitting a function to the experimental data. A summary of the correlations available in literature is shown in Table 15.9.

Table 15.9 Proposed correlations for the structure resistance factor

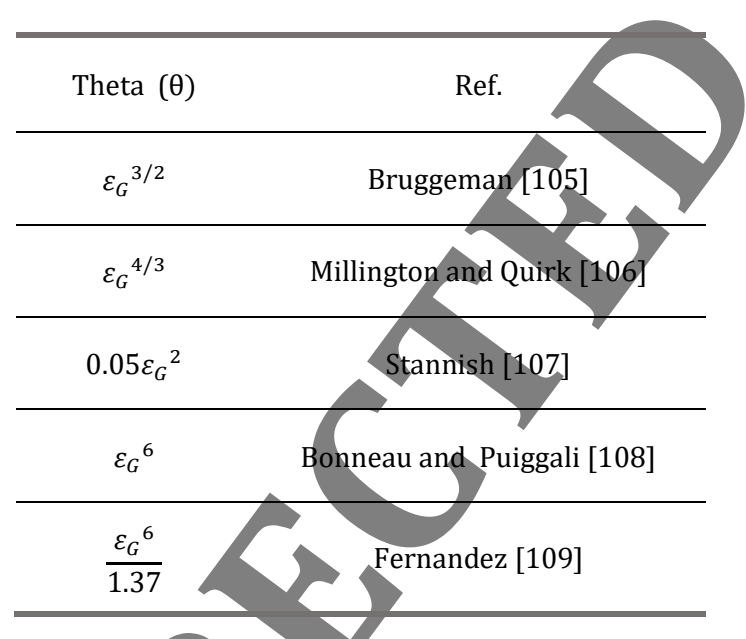

\subsubsection{Heat capacities}

\subsubsection{Heat capacity of biomass}

In the literature devoted to drying of biomass, empirical correlations can be found which combine the influence of temperature and moisture content (liquid and bound water) on the specific heat of biomass. Since there are no theoretical reasons to combine the effects of both parameters into one correlation, the specific heat of biomass and water will be treated separately.

Biomass stârts its degradation in the temperature range from $200{ }^{\circ} \mathrm{C}$ to $250{ }^{\circ} \mathrm{C}$. Therefore the range of temperature for which specific heat of biomass has to be described is more narrow than for gas and vapour compounds. One of the most commonly used correlations is the one obtained experimentally by Grønli [52] for spruce wood and is valid in the range from $80^{\circ} \mathrm{C}$ to $230^{\circ} \mathrm{C}$ :

$$
C_{P, B M}=1500+T
$$

Where $C_{P, B M}$ is the specific heat of biomass. Dupont et al. [110] conducted an analysis of the specific heat of 19 different biomasses in the temperature range from $40{ }^{\circ} \mathrm{C}$ to $80^{\circ} \mathrm{C}$. The result for every biomass shows a linear change of the specific heat with temperature in the investigated range. Taking into account Grønli's correlation, it can be assumed that this trend will be kept until the temperature at which biomass starts to thermally decompose. Averaged for all biomasses used 
in the study of Dupont et al., the correlation between the specific heat and the temperature has

the form:

$$
C_{P, B M}=1032.8+3.783 T
$$

921

922

923

924

925

926

It is proven that the specific heat of biomass is a function of temperature, but in some older publications, it can be found that the parameter as a constant value $[87,91,92]$. Recent work of Gorensek et al. [111] deserves attention in where the authors, starting from fundamentals of thermodynamics, calculated missing heat capacities of artificial, initial components and their transitional forms from the Ranzi scheme. Thereby, they allowed for the implementation of biomass into the model as a mixture of individual bio-components.

\subsubsection{Heat capacity of char}

The most well-known correlation between the specific heat of char and the temperature is the one provided by Raznjevic [67], valid in the range from $0{ }^{\circ} \mathrm{C}$ to $1000{ }^{\circ} \mathrm{C}$ :

$$
C_{P, B C}=1430+0.355 T+6.85 \cdot 10^{-4} T^{2}
$$

Where $C_{P, B C}$ is the specific heat of biochar. In literature, also other correlations for specific heat capacity can be found, e.g. one proposed by Larfeldt et al. [93], valid in the range from $0{ }^{\circ} \mathrm{C}$ to 800 ${ }^{\circ} \mathrm{C}$ :

$$
C_{P, B C}=420+2.09 T-\frac{7.32 \cdot 10^{7}}{T^{2}}
$$

The specific heat for solids at any given time of the reaction is defined as:

$$
C_{P, S}=X_{B M} C_{P, B C}+X_{B C} G_{P, B M}
$$

Where $C_{P, S}$ is the specific heat of the solid.

\subsubsection{Heat capacity of bound and liquid water}

Liquid water heat capacity $\left(C_{P, L}\right)$ at the atmospheric pressure does not change significantly within the range from $20^{\circ} \mathrm{C}$ to $100^{\circ} \mathrm{C}$. Therefore the value of its heat capacity can be assumed as a constant value of $4.20 \mathrm{~kJ} /(\mathrm{kg} \mathrm{K})$, which is an averaged value within the mentioned temperature range. The specific heat of the bound water $\left(C_{P, B}\right)$ is assumed to be slightly higher than the liquid water. Hunt et al. [112] proposed a value of $4.66 \mathrm{~kJ} /(\mathrm{kg} \mathrm{K})$, but this is a rough estimated value, not measured analytically. For the sake of simplicity, the value of $C_{P, B}$ can be treated as equal to $C_{P, L}$ without introducing significant error.

\subsubsection{Heat capacity of gases and vapours}

The specific heat correlation of compounds in the gas mixture applied in a model depends on the complexity of the kinetic scheme. For all low-molecular compounds and most of the highmolecular compounds data can be obtained from the NIST Chemistry WebBook [113] and Gorensek et al. [111]. In case of missing heat capacity data for a specific compound, the authors suggest to find the data record of a compound with similar mass, chemical structure, and chemical properties and treat it as a representative. If more accuracy is needed, the use of thermodynamically based approaches provided by Gordon and McBride [114] is advised. 
For the single component reaction scheme, only four representative compounds have to be described: air, water vapour, gas (1:1 mixture of $\mathrm{CO}$ and $\mathrm{CO}_{2}$ ) and tar (benzene). For the mentioned compounds, Grønli's correlations [52] can be used:

$$
\begin{gathered}
C_{P, \text { Air }}=950+0.188 \mathrm{~T} \\
C_{P, v}=1670+0.64 \mathrm{~T} \\
C_{P, \text { Tar }}=-100+4.4 \mathrm{~T}-1.57 \cdot 10^{-3} \mathrm{~T}^{2} \\
C_{P, \text { Gas }}=770+0.629 \mathrm{~T}-1.91 \cdot 10^{-4} \mathrm{~T}^{2}
\end{gathered}
$$

Where $C_{P}$, is the specific heat and subscript Air, v, Tar and Gas denotes air, water vapour, tars and gases, respectively. The specific heat for the gas-vapour mix at any time-in the process can be obtained from an equation:

$$
C_{P, G}=\frac{\sum_{i}^{N} C_{P, i}<\rho_{i}>^{G}}{<\rho_{G}>^{G}}
$$

Where $C_{P, G}$ is the specific heat of the gas-vapour mix and $C_{P, i}$ is the specific heat for the $i^{\text {th }}$ component of the gas mixture.

\subsubsection{Dynamic viscosities of fluids}

\subsubsection{Dynamic viscosity of gases-vapour mixture}

According to the definition, viscosity is a property of a fluid which indicates its resistance to flow (i.e. continual deformation). The viscosity of fluids depends strongly on temperature and pressure. In the atmospheric pyrolysis, a pressure change during the process is not significant in relation to viscosity, so the pressure influence on fluid viscosity can be omitted. The temperature between the start and the end of the pyrolysis usually exceeds a few hundred degrees, so its influence on the viscosity is significant. Therefore, the temperature dependence of the viscosity should be to implemented into a model.

Similar to heat capacity, the correlations of the viscosity of compounds in the gas mixture applied in a model depend on the complexity of the kinetic scheme. Data for permanent gases and light organic compounds can be found in the NIST database [113]. Heavy organic compounds, for which data is lacking, can be replaced by other, similar compounds and treat them as representatives. The missing data can also be calculated, according to the procedure provided by Poling et al. [80]. For the single component kinetic scheme, the correlations valid in the range from $0{ }^{\circ} \mathrm{C}$ to $1000^{\circ} \mathrm{C}$, for air, water vapour, tars and gases, provided by Grønli [52] can be applied:

$$
\begin{array}{r}
\mu_{G, \text { Air }}=9.12 \cdot 10^{-6}+3.27 \cdot 10^{-8} \mathrm{~T} \\
\mu_{G, v}=-1.47 \cdot 10^{-6}+3.78 \cdot 10^{-8} \mathrm{~T} \\
\mu_{G, \text { Tar }}=-3.73 \cdot 10^{-7}+2.62 \cdot 10^{-8} \mathrm{~T} \\
\mu_{G, \text { Gas }}=7.85 \cdot 10^{-6}+3.18 \cdot 10^{-8} \mathrm{~T}
\end{array}
$$

975 Where $\mu_{G}$ is the dynamic viscosity of gaseous matter and subscript Air, v, Tar and Gas denote air, 976 water vapour, tars and non-condensable gases, respectively. To calculate the viscosity of a gas mix 977 at any given time, the Graham model can be used:

$$
\mu_{G}=\frac{\sum_{i}^{N} \mu_{G, i}<\rho_{i}>^{G}}{<\rho_{G}>^{G}}
$$


Where $\mu_{G}$ is the viscosity of the gas mix and $\mu_{G, i}$ is the viscosity of the $i^{\text {th }}$ component of the mixture. Above mentioned equation (15.78) is appropriate for rough calculations, and it is fully valid only when the molar masses of the mixture components are relatively similar [115]. For a more accurate calculation it is advised to use the Wilkie model with the Herning and Zipperer approximation:

$$
\mu_{G}=\frac{\sum_{i}^{N} \mu_{G, i}<\rho_{i}>^{G} \sqrt{M_{i}}}{\sum_{i}^{N}<\rho_{i}>^{G} \sqrt{M_{i}}}
$$

Where $M_{i}$ is the molar mass of the $i^{\text {th }}$ component in the mixture. In most of the publications related to modelling, the subject of viscosity is treated with neglect. Most of the authors apply the assumption that the viscosity of gases and vapours is invariant to either the gas mix composition and the temperature and its value is constant, equal to $3 \cdot 10^{-5} \mathrm{~Pa}$ s.

\subsubsection{Dynamic viscosity of liquid water}

As it was mentioned in section 15.4.3.3., only the liquid water has the ability to move actively through convection. The viscosity of liquid water as a function of temperature can be calculated with the equation proposed by Grønli [52]:

$$
\mu_{L}=1.40 \cdot 10^{-2}-7.30 \cdot 10^{-5} T+9.73 \cdot 10^{-8} T^{2}
$$

Where $\mu_{L}$ is the liquid water viscosity. Alternatively the correlation proposed by de Paiva Souza et al. [116] can be used:

$$
\log \left(\mu_{L}\right)=-13.73+\frac{1828}{T}+1.97 \cdot 10^{-2} T-1.97 \cdot 10^{-5} T^{2}
$$

\subsubsection{Thermal conductivity}

\subsubsection{Thermal conductivity of biomass}

For particles in the thermally thick regime, thermal conductivity and radiative thermal conductivity have a major influence on the thermal behaviour of the biomass sample. Therefore their appropriate implementation into the model is crucial in terms of the model accuracy.

In Table 15.10 is shown a summary of thermal conductivity data of different biomasses. The thermal conductivity of biomass depends on the bio-composition and structure of the cell wall as well as on the direction of the cut plane (direction of fibres). A rough analysis of the data indicates that the thermal conductivity of hardwoods in the longitudinal direction is c.a. 1.6 times higher than the thermal conductivity in the radial direction. The difference for softwoods is much higher and the ratio of longitudinal to radial thermal conductivity has a value of 2.7. On average, the difference in thermal conductivity in the longitudinal direction between both wood types is relatively low. The difference between both wood types is more visible for the radial thermal conductivity, where hardwoods show c.a. 1.5 times higher thermal conductivity than for softwoods.

Table 15.10 Data of thermal conductivity of different biomasses. (S- softwood, $\mathrm{H}$ - hardwood, in case two values are mentioned for thermal conductivity, they represent longitudinal and radial thermal conductivity respectively)

\begin{tabular}{ccccccc}
\hline $\begin{array}{c}\text { Biomass } \\
\text { species }\end{array}$ & Type & Temp. & $\begin{array}{c}\text { Density } \\
(\text { d.b. })\end{array}$ & $\lambda_{B M, L}$ & $\lambda_{B M, R}$ & Ref \\
\hline$[-]$ & {$[-]$} & {$\left[{ }^{\circ} \mathrm{C}\right]$} & {$\left[\mathrm{kg} / \mathrm{m}^{3}\right]$} & {$[\mathrm{W} /(\mathrm{m} \mathrm{K})]$} & {$[\mathrm{W} /(\mathrm{m} \mathrm{K})]$} & {$[-]$}
\end{tabular}




\begin{tabular}{|c|c|c|c|c|c|c|}
\hline Fir & $S$ & 20 & 370 & 0.305 & 0.112 & \multirow{6}{*}{ [117] } \\
\hline Fir & S & 20 & 430 & 0.387 & 0.118 & \\
\hline Spruce & $S$ & 20 & 385 & 0.422 & 0.087 & \\
\hline Pine & S & 20 & 414 & 0.450 & 0.105 & \\
\hline Pine & S & 20 & 438 & 0.246 & 0.111 & \\
\hline Pine & S & 20 & 440 & 0.358 & 0.313 & \\
\hline Fir & S & 20 & 540 & 0.350 & 0.140 & \multirow{2}{*}{ [118] } \\
\hline Pine & S & 60 & 450 & 0.260 & 0.110 & \\
\hline Pine & S & 20 & 450 & 0.259 & 0.098 & \\
\hline Fir & $S$ & 20 & 540 & 0.340 & 0.138 & \\
\hline Oak & $\mathrm{H}$ & 15 & 710 & 0.361 & 0.209 & \\
\hline Spruce & $S$ & 20 & 414 & 0.279 & & \\
\hline Maple & $\mathrm{H}$ & 30 & 710 & 0.419 & & \\
\hline Beech & $\mathrm{H}$ & 20 & 700 & 0.349 & 0.209 & \\
\hline \multirow{6}{*}{ Birch } & \multirow{6}{*}{$\mathrm{H}$} & \multirow{3}{*}{21} & 680 / 680 & 0.323 & & \multirow{6}{*}{ [120] } \\
\hline & & & $567 / 473$ & 0.293 & & \\
\hline & & & $543 / 443$ & & & \\
\hline & & & $680 / 680$ & & & \\
\hline & & 100 & $567 / 473$ & & 244 & \\
\hline & & & $543 / 443$ & 0.318 & 0.207 & \\
\hline
\end{tabular}

\section{$1014 \quad$ 15.5.8.2. Thermal conductivity of char}

1015 The thermal conductivity of char depends strongly on the initial thermal conductivity of the parent biomass, as well as on the pyrolysis process conditions. In Table 15.11 summarised data of char thermal conductivity originating from different biomasses are shown, at different pyrolysis temperatures. In general, an increase in the pyrolysis temperature results in a decrease in the char thermal conductivity. Data indicate that the thermal conductivity in the longitudinal direction is much less sensitive to the pyrolysis temperature than the one in the radial direction (relative change of 1.3 for the longitudinal direction and 2.4 for the radial direction). For chars originating from softwood and pyrolysed at $470{ }^{\circ} \mathrm{C}$, the longitudinal thermal conductivity is on average five times higher than the radial thermal conductivity. It is suspected that such a large change in the radial direction is related by breaking the continuity of the cell wall's structure caused by the biopolymers degradation.

Table 15.11 Data of thermal conductivity of char originated from different biomasses ( $\mathrm{S}$ - softwood, H - hardwood, GR -grass)

\begin{tabular}{|c|c|c|c|c|c|c|c|}
\hline & Type & Temp. & $\begin{array}{c}\text { Temp. of } \\
\text { pyro. }\end{array}$ & $\begin{array}{l}\text { Density } \\
\text { (d.b.) }\end{array}$ & $\lambda_{B C, L}$ & $\lambda_{B C, R}$ & Ref \\
\hline & {$[-]$} & {$\left[{ }^{\circ} \mathrm{C}\right]$} & {$\left[{ }^{\circ} \mathrm{C}\right]$} & {$\left[\mathrm{kg} / \mathrm{m}^{3}\right]$} & {$[\mathrm{W} /(\mathrm{m} \mathrm{K})]$} & {$[\mathrm{W} /(\mathrm{m} \mathrm{K})]$} & {$[-]$} \\
\hline \multirow{4}{*}{ Fir } & & & 270 & 340 & 0.338 & 0.112 & \multirow{7}{*}{ [117] } \\
\hline & & & 450 & 264 & 0.255 & 0.034 & \\
\hline & & & 270 & 331 & 0.325 & 0.087 & \\
\hline & $S$ & 50 & 450 & 255 & 0.223 & 0.032 & \\
\hline \multirow{2}{*}{ Spruce } & & & 270 & 337 & 0.344 & 0.105 & \\
\hline & & & 450 & 249 & 0.186 & 0.052 & \\
\hline Pine & & & 270 & 330 & 0.265 & 0.118 & \\
\hline
\end{tabular}




\begin{tabular}{ccccccc} 
& & 450 & 248 & 0.247 & 0.049 \\
Pine & & 270 & 360 & 0.198 & 0.111 \\
& & 450 & 251 & 0.188 & 0.046 \\
Pine & & 270 & 364 & 0.180 & 0.131 \\
\hline Maple & H & - & 450 & 269 & 0.216 & 0.072 \\
\hline Miscanthus & GR & - & 500 & - & 0.105 & 0.071 \\
\hline
\end{tabular}

1029

1030

1031

1032

1033

1034

1035

1036

1037

1038

1039

1040

1041

1042

1043

1044

1045

1046

1047

1048

1049

$$
\lambda_{S, D}=X_{B M} \lambda_{B M, D}+X_{B C} \lambda_{B C, D}
$$

The thermal conductivity of solids in a given direction $(D=L, R, T)$ at any given time of the reaction is defined as:

Where $\lambda_{B M, D}$ and $\lambda_{B M, D}$ denote the thermal conductivity in a given direction for biomass and biochar, respectively.

\subsubsection{Thermal conductivity of liquid and bound water}

The thermal conductivity of liquid water as a function of temperature can be obtained through the correlation of data from the NIST database [113]:

$$
\lambda_{L}=0.7695+7.5 \cdot 10^{-3} T-1 \cdot 10^{-5} T^{2}
$$

In literature, constant values of thermal conductivity of liquid water, i.e. $0.658 \mathrm{~W} /(\mathrm{m} \mathrm{K})$ [52] can be found. Due to a lack of experimental data regarding the thermal conductivity of bound water, it has to be assumed that its thermal conductivity value is similar to that of liquid water.

\subsubsection{Thermal conductivity: Gas mixture}

The thermal conductivity of most of the permanent gases, light and heavy organic compounds can be found in tables $[67,122,123]$ or in the NIST database [113]. Heavy organic compounds, for which data is lacking, can be replaced by other, similar compounds and treat them as representatives. The missing data can also be calculated, according to the procedure provided by Poling et al. [80]. For the single component kinetic scheme, correlations between the thermal conductivity and the temperature for air, water vapour and permanent gases are based on data from NIST [113], and they are valid in range from $0^{\circ} \mathrm{C}$ to $1000^{\circ} \mathrm{C}$. The correlation for tar (benzene) can be obtained from the work of Zaitseva et al. [124], and it is valid in the range from $320^{\circ} \mathrm{C}$ to $660^{\circ} \mathrm{C}$.

$$
\begin{aligned}
& \lambda_{G, \text { Air }}=9.3 \cdot 10^{-3}+6 \cdot 10^{-5} \mathrm{~T} \\
& \lambda_{G, \mathrm{v}}=-8.1 \cdot 10^{-3}+1 \cdot 10^{-3} \mathrm{~T} \\
& \lambda_{G, \text { Tar }}=-5.07 \cdot 10^{-1}+1.1 \cdot 10^{-3} \mathrm{~T} \\
& \lambda_{G, \text { Gas }}=1.01 \cdot 10^{-2}+4 \cdot 10^{-5} \mathrm{~T}
\end{aligned}
$$

1050 Analogous to the viscosity, the thermal conductivity of a gas mixture at any time in the pyrolysis process can be calculated with the equation: 


$$
\lambda_{G}=\frac{\sum_{i}^{N} \lambda_{G, i}<\rho_{i}>^{G}}{<\rho_{G}>^{G}}
$$

1052

1053

1054

1055

1056

1057

1058

1059

1060

1061

1062

1063

1064

1065

1066

1067

1068

1069

1070

1071

1072

1073

1074

1075

1076

1077

1078

1079

1080

Where $\lambda_{G, i}$ is the thermal conductivity of the $i^{\text {th }}$ component in the gas mix. For more accurate calculations, the Wassilijewa's equation with the Herning and Zipperer approximation can be used:

$$
\lambda_{G}=\frac{\sum_{i}^{N} k_{G, i}<\rho_{i}>^{G} \sqrt{M_{i}}}{\sum_{i}^{N}<\rho_{i}>^{G} \sqrt{M_{i}}}
$$

Where $M_{i}$ is the molar mass of the $i^{\text {th }}$ component in the mixture. Many authors use simplifications and implement the thermal conductivity of the gas mix as a constant value in the range from 0.025 $\mathrm{W} /(\mathrm{m} \mathrm{K})$ to $0.026 \mathrm{~W} /(\mathrm{m} \mathrm{K})[52,56,91,103]$.

\subsubsection{Radiative heat transfer}

When the pyrolysis temperature exceeds $600{ }^{\circ} \mathrm{C}$, the share of the heat transferred through radiation within the particle starts to become significant. In such cases, implementation of the radiative heat transfer into the model is necessary. Radiative thermal conductivity within a particle can be defined as:

$$
\lambda_{\text {rad }}=A \ell_{n} \sigma T^{3}
$$

Where $\lambda_{\text {rad }}$ is the radiative thermal conductivity, $\ell_{n}$ is the photon's mean free path, $\sigma$ is the Stefan-Boltzman constant and $A$ is the coefficient of the radiative model. In Table 15.12 are presented the most commonly used correlations for radiative thermal conductivity, others can be found in work of Grønli [52].

Table 15.12 Models of radiative thermal conductivity

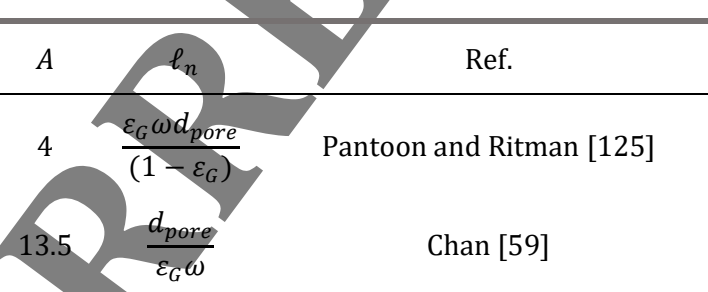

Di Blasi [92]

Where $\omega$ is the surface emissivity and $d_{\text {pore }}$ is the average diameter of the pores, calculated as:

$$
d_{\text {pore }}=X_{B M} d_{\text {pore }, B M}+X_{B C} d_{\text {pore }, B C}
$$

Where $d_{\text {pore }}$ is the average pore's size and subscripts BM and BC denote the biomass and the biochar, respectively. The average pore size of biomass or biochar in the equation above is obtained from the whole range of pores existing in the structure (micro-, meso- and macropores). Therefore its value should be obtained by helium pycnometry.

Regarding the influence of the pore size on the radiative thermal conductivity, the work of the Janse et al. [104] is worth to mention. They proposed a division of the radiative thermal conductivity in the macropore radiative conductivity and the micropore radiative conductivity. Such an approach seems intuitively reasonable and in theory, it should be more accurate. Nonetheless, the lack of reliable data regarding the pore size distribution of the biochar and its 
1081

1082

1083

1084

1085

1086

1087

1088

1089

1090

1091

1092

1093

1094

1095

1096

1097

1098

1099

1100

1101

1102

1103

1104

1105

1106

1107

1108

1109

evolution throughout pyrolysis does not allow to obtain solid proof. In the literate applications of Janse et al.'s radiative heat transfer model with an averaged pore size $[57,65]$ can be found.

\subsubsection{Effective thermal conductivity}

The effective thermal conductivity depends on the following factors: anisotropy of the structure, porosity and pore size distribution, bio-composition of the cell wall and water content. In literature examples of correlations for the thermal conductivity of wet biomass particles obtained empirically can be found. In most cases, they were applied for the description of a drying process, not pyrolysis combined with drying $[50,72,84,86,126]$. In order to describe the thermal conductivity of biomass, the following general equation is often used:

$$
\lambda_{e f f, D}=\lambda_{\text {cond }, D}+\lambda_{\text {rad }}
$$

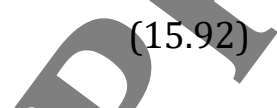

Where $\lambda_{e f f, D}$ is the effective thermal conductivity, $\lambda_{\text {cond,D }}$ is the thermal conductivity, $\lambda_{\text {rad }}$ is the internal radiative thermal conductivity and the subscript $\mathrm{D}$ denotes the direction of the conduction. The thermal conductivity can also be treated as a function based on conduction through the solid matter with respect to the heat transfer direction $\left(\lambda_{S, D}\right)$, the conduction through the liquid and bound water $\left(\lambda_{L}, \lambda_{B}\right)$ and the conduction through gas filling the pores $\left(\lambda_{G}\right)$. The last three terms are not directionally dependent.

$$
\lambda_{\text {cond }, D}=f\left(\lambda_{S, D}+\lambda_{L}+\lambda_{B}+\lambda_{G}\right)
$$

The share of each thermal conductivity component is proportional to its volume fraction, so the effective thermal conductivity within a particle can be defined as:

$$
\lambda_{e f f, D}=\left(\varepsilon_{S} \lambda_{S, D}+\varepsilon_{L} \lambda_{L}+\varepsilon_{B} \lambda_{B}+\varepsilon_{G} \lambda_{G}\right)+\lambda_{\text {rad }}
$$

More detailed approaches on the modelling of the thermal conductivity can be found in work of Suleiman et al. [120], Thunman and Leckner [127], Blondeau and Jeanmart [40] and Gentile et al. [53]. All mentioned approaches are based on the comprehensive thermal conduction model developed by Kollmann and Côte [128].

\subsubsection{Surface emissivity}

Radiative heat emissivity from natural surfaces is usually modelled as a "grey body". According to the definition and the Stefan-Boltzmann law, a "grey body" is an intermediate material between a perfect absorber of light (ideal "black body") and a perfect reflector of light (ideal "white body"). The value of the emissivity of the "grey body" depends on the surface's temperature, colour and roughness. For biomass, emissivity $\left(\omega_{B M}\right)$ is usually assumed to be in the range between 0.7 and $0.85[64,65]$ and for biochar $\left(\omega_{B C}\right)$ in the range between 0.9 and 0.95 [52,59]. The surface emissivity $(\omega)$ at any time of the process can be defined as:

$$
\omega=X_{B M} \omega_{B M}+X_{B C} \omega_{B C}
$$

\subsubsection{Particle shrinking}

Drying and thermal degradation of a biomass particle have an influence not only on its porosity and thermo-physical properties but also on its overall geometry and shape. To model a particle's 
1113

1114

1115

1116

1117

1118

1119

1120

1121

1122

1123

1124

1125

1126

1127

1128

1129

1130

1131

1132

1133

1134

1135

1136

1137

1138

1139

1140

1141

1142

1143

1144

1145

change in geometry and shape, usually, one out of three methods of shrinking process description is applied: uniform shrinkage, shrinking shell, or shrinking cylinder.

An analysis of shrinkage during pyrolysis shows that final shrinkage in the longitudinal direction is lower than in the radial direction. Additionally, for small particles, the shrinking takes place mostly at the end of the conversion. During the conversion under a high heating rate, strong mechanical tensions occur within a particle, which leads to particle cracking and in some cases, even to the fragmentation of a particle. Besides the reduction in particle shape by shrinking, the expansion via the swelling can take place. The expansion can be observed usually at the beginning of the conversion, especially for large particles [129]. The details regarding cracking and swelling are not incorporated in mentioned models of shrinking.

A detailed description of mentioned shrinking models can be found in the work of Bryden et al. [61] and Bellais [130]. The most commonly used shrinking model is the uniform shrinking model, so its basis will be briefly described here. Shrinking in a selected direction can be defined as [61]:

$$
f_{D}=\frac{\text { current dimension }}{\text { original dimension }}=\frac{L_{D}}{L_{D 0}}
$$

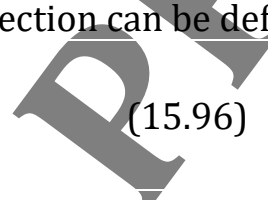

Where $f_{D}$ is the shrinkage factor in the D direction, $L_{D}$ is the dimension after shrinkage in the $\mathrm{D}$ direction and $L_{D 0}$ is the original dimension in the $\mathrm{D}$ direction. The uniform shrinking model assumes, that particle size change is directly proportional to the mass loss, so it can be stated that:

$$
f_{D}=\left[(\bar{\eta}-1) p_{D}+(\overline{\mathrm{M}}-1) m_{D}\right]
$$

Where $\bar{\eta}$ is the conversion extent of pyrolysis, averaged over the particle's geometry, $p_{D}$ is the parameter of final shrinkage due to pyrolysis in direction $D, \bar{M}$ is the progress of the particle's drying, averaged over the particle's geometry, $m_{D}$ is the parameter of final shrinkage due to drying in the $D$ direction. The drying influence on the shrinkage in any direction is not large (6-7\%) [61], so its omission does not introduce significant accuracy loss in modelling [131]. Applying the aforementioned simplification, the following equation is obtained:

$$
f_{D}=\left[(\bar{\eta}-1) p_{D}\right]
$$

The averaged conversion extent of the pyrolysis reaction is defined as:

$$
\bar{\eta}=\frac{\text { current mass of biomass }}{\text { inital mass of biomass }}=\frac{\left.<\rho_{B M}\right\rangle}{<\rho_{B M 0}>}
$$

Where $\left\langle\rho_{B M 0}>\right.$ is the initial apparent density of biomass. A more in-depth description of changes to the conservation equations due to implementation of the uniform shrinking model can be found in the work of Bryden et al. [61] and Anca-Couce et al. [56].

Exemplary final shrinkage parameters that can be found in the literature are summarised in Table 15.3. The symbols $\alpha, \beta$ and $\gamma$ denote the final shrinkage in the longitudinal $\left(p_{L}\right)$, radial $\left(p_{R}\right)$ and transversal $\left(p_{T}\right)$ direction, respectively. The data in the table indicates that the final particle shrinkage depends not only on the pyrolysis temperature but also on the heating rate.

Table 15.13 Exemplary values of final shrinkage parameter in pyrolysis, and obtained experimentally (HR - heating rate).

\begin{tabular}{ccccc}
\cline { 2 - 4 }$p_{L}=\alpha$ & $p_{R}=\beta$ & $p_{T}=\gamma$ & Ref. \\
\hline 0.34 & 0.50 & 1 & [93] \\
0.30 & 0.40 & 1 & low HR [132] \\
0.30 & $0.05-0.20$ & 1 & high HR [132] \\
\hline
\end{tabular}


An extensive analysis of particle shrinkage was performed by Davidson et al. [133]. It resulted in a correlation between the highest temperature in pyrolysis and the final shrinkage parameter in direction $D$. The correlation is valid for temperatures from $350{ }^{\circ} \mathrm{C}$ to $700{ }^{\circ} \mathrm{C}$.

$$
p_{D}=a_{D}^{2}\left[a_{D}+b_{D} T+c_{D} T^{2}\right]
$$

1150

1151

1152

1153

1154

1155

1156

1157

1158

1159

1160

1161

1162

1163

1164

1165

Where $a_{D}, b_{D}$ and $c_{D}$ are correlation parameters obtained by fitting to experimental data. Their values are shown in Table 15.14.

Table 15.14 Parameters of Davidson et al. correlation [133] (D - direction, L - longitudinal, R- radial, T - tangential)

\subsection{Boundary conditions}

\begin{tabular}{cccc}
\hline $\mathrm{D}$ & $a_{D}$ & $b_{D}$ & $c_{D}$ \\
\hline $\mathrm{L}$ & -4.7 & $1.08 \cdot 10^{-2}$ & $-5.86 \cdot 10^{-6}$ \\
$\mathrm{R}$ & 4.4 & $-8.56 \cdot 10^{-3}$ & $4.55 \cdot 10^{-6}$ \\
$\mathrm{~T}$ & -1 & $3.95 \cdot 10^{-3}$ & $-2.62 \cdot 10^{-6}$ \\
\hline
\end{tabular}

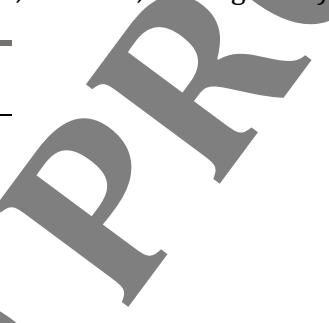

\subsubsection{Boundary conditions equations}

Boundary conditions are the drivers of the modelled process through the description of phenomena occurring on the geometrical surface of a particle. In other words, boundary conditions define the behaviour of the nodes located on the geometry edge. In the most general case, they are defined as [134]:

- For pressure:

- For heat transfer:

$$
\left.\nabla\left(\lambda_{e f f} \nabla T\right)\right|_{x=x_{p}}=h_{T}\left(T_{\text {flow }, \infty}-\left.T\right|_{x=x_{p}}\right)+\sigma \omega\left(T_{\text {wall }}^{4}-\left.T^{4}\right|_{x=x_{p}}\right)
$$

- For mass transfer:

$$
\left.D_{e f f} \nabla\left(<\rho_{i}>^{G}\right)\right|_{x=x_{p}}=h_{m}\left[\rho_{i, \infty}-<\rho_{i}>\left.^{G}\right|_{x=x_{p}}\right]
$$

Where $\Lambda_{x=x_{p}}$ denotes the position ( $\mathrm{x}_{\mathrm{p}}$ point of the surface, " $\mathrm{x}$ " can be adapted according to the appropriate coordinate system), $P_{\infty}$ is the pressure of the environment (ambient), $h$ is the convective transfer coefficient, subscript $T$ and $m$ denote heat and mass respectively, $T_{\text {flow, } \infty}$ is the temperature of the flowing fluid at a considerable distance from the particle's surface, $T_{\text {wall }}$ is the temperature of the reactor wall, $\sigma$ is Stefan-Boltzmann coefficient, $\omega$ is surface emissivity and $\rho_{i, \infty}$ is the density of the $i^{t h}$ compound at a considerable distance from the particle's surface. Even though the radiative heat transfer at a temperature below $600{ }^{\circ} \mathrm{C}$ does not have a large share in the total heat exchange [135], its implementation is not complex and can result in improvements in model accuracy. 
1176

1177

1178

1179

1180

1181

1182

1183

1184

1185

1186

1187

1188

1189

1190

1191

1192

1193

1194

1195

1196

1197

1198

1199

1200

Convective heat and mass transfer coefficients can be obtained from correlations of the dimensionless numbers.

- The convective heat transfer coefficient from the Nusselt number:

$$
N u=\frac{h_{T} L}{\lambda_{\text {eff }}}
$$

- The convective mass transfer from the Sherwood number:

$$
S h=\frac{h_{m} L}{D_{\text {eff }}}
$$

Where $L$ is the characteristic dimension of a particle, $h_{T}$ is the convective heat transfer coefficient, $h_{m}$ is the convective mass transfer coefficient, $\lambda_{e f f}$ is the effective thermal conductivity and $D_{e f f}$ is the effective diffusion coefficient. For laminar flow, the dimensionless numbers can be obtained from flow-shape correlations presented in Table 15.15.

\begin{tabular}{|c|c|c|}
\hline Particle shape & Convective heat transfer & Convective mass transfer \\
\hline $\begin{array}{c}\text { Flat plate, } \\
\text { (Kerith and Black eq.) }\end{array}$ & $N u=0.644 \operatorname{Re}^{0.5} \operatorname{Pr}^{0.33}$ & $S h=0.644 R e^{0.5} S c^{0.33}$ \\
\hline $\begin{array}{l}\text { Cylindrical } \\
\text { (Churchill and } \\
\text { Bernstein eq.) }\end{array}$ & $N u=0.3+\frac{0.62 R e^{0.5} \operatorname{Pr}^{0.33}}{\left[1+\left(\frac{0.4}{P r}\right)^{0.66}\right]^{0.25}}[1+$ & $S h=0.3+\frac{0.62 R e^{0.5} S c^{0.33}}{\left[1+\left(\frac{0.4}{S c}\right)^{0.66}\right]^{0.25}}\left[1+\left(\frac{R e}{2.82 \cdot 10^{5}}\right)^{0.625}\right]^{0.8}$ \\
\hline $\begin{array}{c}\text { Spherical } \\
\text { (Ranz-Marshall eq.) } \\
\text { and } \\
\text { (Whitaker eq.) }\end{array}$ & $N u=2+\left[0.4 R e^{0}\right.$ & $\begin{array}{c}S h=2+\left[0.6 R e^{0.5} S c^{0.33}\right] \\
S h=2+\left[0.4 R e^{0.5}+0.06 R e^{0.66}\right] S c^{0.4}\left(\frac{\mu_{\infty}}{\mu_{s}}\right)^{0.25}\end{array}$ \\
\hline
\end{tabular}

Table 15.15 Dimensionless number correlations as a function of shape $[134,136]$.

Where Pr is Prandtl's number, Sc is Schmidt's number, $\mu$ is the dynamic viscosity of the gas mix, and subscript $\infty$ and $S$ denote the free stream and the surface (on the fluid's side) respectively. Above mentioned correlations are valid only for particles immersed in a single-phase flow. It is advised to use other correlations to calculate the convective heat and mass transfer coefficient of particles immersed in two-phase flows (e.g. gas-solid systems in a fluidised bed), [92,137-140].

Rapid evaporation or ignition of evolved pyrolysis gases can cause a temporary disturbance in the convective transfer. In order to account for it in a model, Stefan's correlation can be used to calculate the mass and heat convective transfer coefficients with an extensive outflow from surfaces $[57,65,92,101]$. Correlations are defined as:

- Heat transfer:

$$
h_{T s}=\frac{A_{S} u_{G} \varepsilon_{G}<\rho_{G}>^{G} C_{P, G}}{\exp \left(\frac{A_{S} u_{G} \varepsilon_{G}<\rho_{G}>^{G} C_{P, G}}{h_{T}}\right)-1}
$$

- Mass transfer:

$$
h_{m s}=\frac{A_{S} u_{G}}{\exp \left(\frac{A_{S} u_{G}}{h_{m}}\right)-1}
$$


Where $h_{T s}$ is the convective heat transfer coefficient with surface outflow, $h_{m s}$ is the convective mass transfer coefficient with surface outflow and $A_{S}$ is the external surface area of a particle.

In literature, exemplary values of the convective heat transfer coefficient can be found: flat plate - $5 \mathrm{~W} /\left(\mathrm{m}^{2} \mathrm{~K}\right)$ [52], sphere $-20 \mathrm{~W} /\left(\mathrm{m}^{2} \mathrm{~K}\right)$ [28], shapes with different size from $8.4 \mathrm{~W} /\left(\mathrm{m}^{2} \mathrm{~K}\right)$ to 20 $\mathrm{W} /\left(\mathrm{m}^{2} \mathrm{~K}\right)$ [141], particles in a fixed bed $-50 \mathrm{~W} /\left(\mathrm{m}^{2} \mathrm{~K}\right)$ [142] or particles in a fluidised bed -400 $\mathrm{W} /\left(\mathrm{m}^{2} \mathrm{~K}\right)$ [143]. Not as many examples for the convective mass transfer coefficient can be found: flat plate $-0.03 \mathrm{~m} / \mathrm{s}$ [52]. It is possible that many authors consider that the mass transfer from a particle is not hindered nor enhanced. Therefore the convective mass transfer coeffieient is equal to the superficial gas velocity on the surface.

\subsection{Reactor model and multiscale}

The gases and the solid phase (processed biomass) in a given reactor have significant differences in physical, chemical and thermal behaviour. Therefore, in this section, the description of each phase separately needs to be considered as well as interactions between the phases.

\subsubsection{Lagrangian method - particle movement description}

In reactor systems, the movement of every single particle is independent. The method which allows for describing the behaviour of each individual particle is the Lagrangian approach, which is based on Newton's second law of motion $[56,144]$. In the Lagrangian framework, each particle is modelled with its own body (subdomain), which moves independently in an applied geometry according to the forces affecting the particle. This framework allows for investigating the timeposition relation of each particle (e.g. trajectory).

The framework of the Lagrangian method also allows for the implementation of mechanical interactions between particles and between phases. Consecutively, it opens the possibility for implementation and investigation of particle-particle and particle-wall interactions. The visualisation of the basic difference between the Eulerian and the Lagrangian approach is shown in Fig 15.7.

\section{EULERIAN}

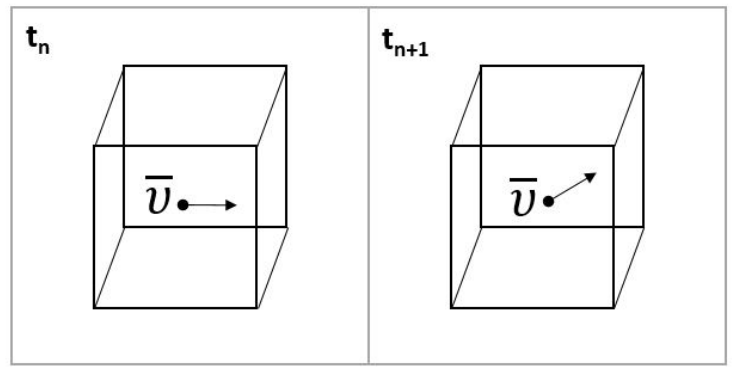

Fixed point

$P[x, y, z, t]$
LAGRANGIAN

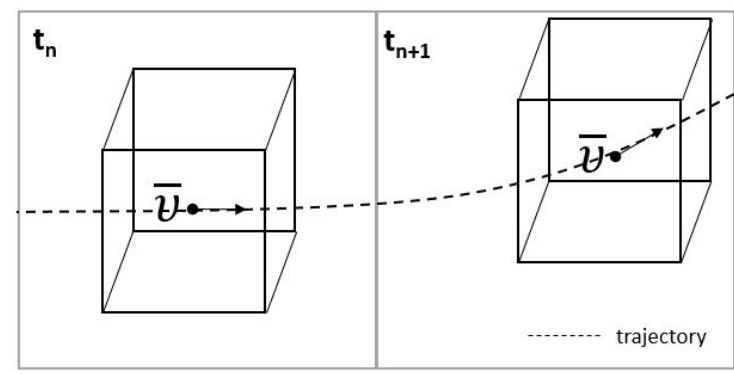

Moving point

$P[x(t), y(t), z(t), t]$

Fig. 15.7 Simplified visualisation of the difference between Eulerian and Lagrangian approach.

\subsubsection{Methods of two-phase flow description}

The Eulerian approach is sufficient to describe a single-phase flow and all significant unit processes occurring in it. Unfortunately, such an approach may not be sufficient to describe twophase flows (e.g. gas-solid systems) appropriately.

A comprehensive and complete description of the behaviour of two-phase flow is provided by a combination of Computational Fluid Dynamics (CFD) with the Discrete Element Method (DEM) 
resulting in the so-called Eulerian-Lagrangian approach (CFD-DEM method). The first part of the name indicates that the gas phase description (fluid with continuum properties) is done according to the Eulerian method. In the Eulerian approach, fluid properties are stored in grid nodes of the applied geometry. The fluid movement does not interfere with the grid arrangement. The second part of the name indicates that the description of the solid phase (particles) is done with the Lagrangian approach. In this approach, solid particles are not linked to the grid used for modelling fluid dynamics, and the subdomains of particles can move freely through the applied geometry. Nevertheless, both phases are interconnected, so, e.g. the movement of the particles causes changes in the fluid phase, and the flow of the fluid can alter the movement of particles.

With an increase in the number of investigated particles as well as with an increase of the complexity of the single-particle behaviour, the quantity of data that needs to be handled by the solver grows exorbitantly. Therefore, a proper description of the investigated system with the full Eulerian-Lagrangian method, besides an in-depth knowledge about its fundamentals, needs robust numerical software tools and powerful computing hardware.

The Discrete Phase Model (DPM) is a hybrid method, and it is based on a partial simplification of the DEM method. The DPM method still has its base in the Lagrangian description and takes into accountsthe particle's movement resulting from forces like: gravity, drag force, pressure force and Magnus force, but the particle-particle collisions are neglected. Additionally, the Discrete Phase Model method omits the fluid volume's displacement by particles, so the volume of a fluid phase remains constant. Recommendations with respect to choosing the simplification from DEM to DPM, are not clear in the literature. The cause of this can be linked to the difference in types of reactors that were modelled with the use of the simplification. The most general recommendation is to apply the simplification in cases when the solid phase is strongly dispersed, and its volume fraction is less than 5 vol. \% [145].

The Dense Discrete Phase Model method (DDPM), an improved version of the DPM is an another, more recently developed hybrid method. The DDPM method is capable of handling higher volume fractions of the solid phase, and it has an in-built particle-particle collision submodel through a collision component taken from the DEM method. One of the drawbacks of the DDPM method is that the flow around particles is not taken into account during the simulation, so the dynamic behaviour of particles still can differ from reality. Both hybrid approaches (simplifications) lead to a significantreduction in the computational burden in comparison to the full DEM description method. Also, the influence of applying these simplifications on the accuracy loss strongly depends on the modelled scenario (reactor type, number of particles and their size).

In peculiar cases, when the size of the particles is sufficiently small and the particles are strongly dispersed among the fluid phase (suspension), there is the possibility of a strong simplification with the assumption that the particles suspended in a fluid are "dissolved" in it. Therefore they can be treated as part of the fluid, and they can behave as such (quasi-continuous solid phase). The method of describing a two-phase system where both phases are treated as a continuum is called the Eulerian-Eulerian approach. It indicates that both phases, fluid and solid, are described by the Eulerian approach, so the model does not distinguish each particle in the solid phase. Therefore in this approach, it is impossible to investigate the single particle movement. The Eulerian-Eulerian approach is the least computationally burdening method of simulating two-phase flow. Moreover, the simplification is very convenient in terms of mathematical description. Expressions used for describing the movement, thermal and chemical behaviour of the solid phase have the same construction as those used for the fluid phase description. There is a strong restriction regarding the application of this simplification. The Eulerian-Eulerian approach for particles with relatively large size introduces a significant deviation from reality in the model. In such cases, the result of the simulation is burdened with a considerable inadequacy, so its accuracy is low. 
1284

1285

1286

1287

1288

1289

1290

1291

1292

1293

1294

1295

1296

1297

1298

1299

1300

1301

1302

1303

1304

1305

1306

1307

1308

1309

1310

1311

1312

1313

1314

1315

1316

1317

1318

1319

1320

1321

1322

1323

1324

1325

1326

1327

1328

1329

The fluid phase in a reactor is always described with the Eulerian approach. In comparison to the description of the solid phase, it makes the fluid phase a less challenging part of the reactor model The description of the fluid phase has to contain, among others: fluid motion within the reactor geometry, changes of fluid phase volume due to particle movement and rotary elements (if any), the heat exchange between the fluid and reactor's walls and particles. The description of the fluid phase in the reactor has to cope also with the chemical behaviour of the compounds (e.g., secondary tar cracking) that are contained in it.

As it has been mentioned, the possibility of simplifying the description of the two-phase flow into the a quasi-one phase fluid flow (Eulerian-Eulerian) is only valid when particles immersed in the fluid are sufficiently small. To assess if this simplification is valid, values of two nondimensional numbers have to be checked: the thermal Biot number (Bi) and the Pyrolysis number (Py), the latter is also called reversed thermal Thiele modulus [56]. Those numbers indicate to which thermal regime the investigated particles belong. Each of the regimes indicate which thermal phenomena (chemical reactions, intra-particle or extra-particle heat exchange) have the strongest influence on the rate of the particle's conversion [24,91,146-148]. Particles can be assigned to one of the four following thermal regimes: pure kinetic, thermally thin, thermal wave and thermally thick.

The simplification through the Euler-Euler approach is the most valid for particles in the pure kinetic regime, whose size usually is smaller than $1 \mathrm{~mm}$ in any direction [5]. Conversion of particles in the thermal thin regime is also driven mostly by the reaction kinetics, but also external heat transfer starts to play a significant role. Due to a relatively small size, those particles do not show high thermal or internal pressure gradients during conversion. The application of this simplification for particles in the thin thermal regime is not advised, but it would not introduce a critical error to the model. For this regime, the dilution of the solid phase also has to be taken into account. In case of a highly concentrated solid phase, the Eulerian-Eulerian approach is not valid, so more sophisticated description methods (DPM or DDPM) have to be applied to obtain more accurate and reliable description.

The conversion of particles assigned to the thermal wave regime is mostly driven by the internal and external heat transfer. Additionally, a significant temperature and pressure gradient is formed during the conversion_For particles in the thermal wave regime, the particle's location during the process starts to play a major role in its conversion. Therefore, applying the Euler-Euler simplification is not valid for particles in this regime, and thus they have to be described with a Lagrangian approach. It is expected that, in the thermal wave regime the conversion of the particle takes place in a thin surface front, so the assumption that the conversion front thickness strives to 0 , is not a large departure from reality. Such an approach opens a possibility of a partial simplification of describing the conversion process. The simplification can be made by implementation of the unreacted shrinking core model or the layer model $[5,24,149]$.

The internal heat transfer has the largest share in the control of the conversion of particles in the thermally thick regime. To this regime are assigned the largest particles, which show the highest temperature and pressure gradients during conversion. There is no stiff border, from which point the particles have to be assigned to the thermally thick regime. In literature, it can be found that the particle is considered to be in the mentioned regime if the Bi number is higher than 40 or 100 and the thermal Thiele modulus (1/Py) number is higher than 100 or $1400[148,150]$. The conversion of the particle in the thermally thick regime is the most complex and cannot be simplified, so only a detailed description via the Eulerian-Lagrangian approach is valid (DDPM or DEM). 
1331

1332

1333

1334

1335

1336

1337

1338

1339

1340

1341

1342

1343

1344

1345

1346

1347

1348

1349

1350

1351

1352

1353

1354

1355

1356

1357

1358

1359

1360

1361

1362

1363

1364

1365

1366

1367

1368

1369

1370

1371

1372

1373

1374

1375

1376
For fixed bed reactors, the only limitation for the particle size are the reactor dimensions. Therefore relatively large biomass particles (e.g. logs or large chunks) can be processed in a fixed bed. For this reactor type, the movement of particles is negligible, and the mixing of solids is insignificant. Taking this into account, Wurzenberger et al. [151] proposed the Representative Particle Model (RPM), suitable for the description of the conversion of single particles in fixed bed reactors. The method assumes that parameters of biomass conversion can be treated as homogenous for the whole reactor, so all processed particles show the same behaviour. In consequence, it leads to the conclusion that for the RPM, the single-particle model needs to be solved for one representative particle only once for the applied boundary and initial conditions. Application of the RPM method for modelling fixed beds reduces the computational time significantly and shows moderately good agreement with experimental results $[5,152,153]$.

An additional challenge is brought into the reactor model description for systems in which particles are in motion. Movement of particles can be driven by changes in pressure of a fluid (pneumatically driven) or by the physical forces transmitted to the particles via the reactor's rotary elements (mechanically driven). In the second scenario, the moving element also has an influence on the gas motion in the reactor, and this needs to be taken into account in the description of a model. The selection of the driver of the particle's movement imposes practical boundaries on the size of particles that can be processed in the reactor.

For fluidised beds, the particle size has to be significantly small to be able to be suspended and/or dragged by the fluidising gas. In general, the size of particles that can be applied in fluidised bed reactors does not exceed 2-3 mm. Application of such small particles in fluidised bed reactors opens possibilities for model simplification (Eulerian-Eulerian, DPM or DDPM). An implementation of the simplification leads to a significant reduction in complexity of the description and simultaneously, it lowers the computational burden.

In processing in rotary reactors (auger/screw or rotary kiln reactors), the size of particles is usually larger than in fluidised bed reactors. The maximum size of particles for rotary reactors is limited by the dimensions of the reactor and its moving parts (e.g. size of a screw and its pitch), the reactor's mechanical durability and the homogeneous distribution of solid material in the reactor. The particles processed in rotary reactors cannot be assigned to the kinetic thermal regime due to their large size. Therefore there is no possibility of applying the Euler-Euler approach for those systems. For rotary reactors, the Eulerian-Lagrangian approach of the twophase flow has to be implemented (DPM, DDPM, or DEM). It has to be kept in mind that for rotary reactors, the influence of the movement of the reactor's elements as well as of the particles on the fluid phase has to be included in the model description. Models for rotary reactors are the most demanding, both for the modeller (interdependences between phases, number of correlations and parameters), as well as for the software and hardware used to conduct computation on such complex systems.

An extensive and comprehensive overview of the application of different approaches for describing specific reactor modelling cases can be found in the recent work of Xiong et al. [154]. The work contains numerous references to examples from literature, so the authors strongly recommend this review for readers interested in the subject. Among many others, the works of Subramaniam [155], Ku et al. [156,157] and Xie et al. [158] are worth to mention, as they contain the mathematical description of the Eulerian-Lagrangian method, as well as the work of Funke et al. [159] in which, for the first time the heat transfer between particles in an auger type reactor was calculated using a combined fundamental heat transfer model with DEM simulation. 
1378

1379

1380

1381

1382

1383

1384

1385

1386

1387

1388

1389

1390

1391

1392

1393

1394

1395

1396

1397

1398

1399

1400

1401

1402

1403

1404

1405

1406

1407

1408

1409

1410

1411

1412

1413

1414

1415

1416

1417

1418

1419

1420

1421

1422

1423

1424

Increase in complexity of a comprehensive model for biomass conversion, in principle, is done to bring a model closer to reality and improve its prediction accuracy. Simultaneous application of detailed models causes the issue requiring a vast amount of data and correlations that need to be handled and computed by a solver. A vast increase in computational load requires simultaneously a higher need for hardware power to obtain adequate solving efficiency. A very complex model and limited computational resources result in elongated computational time, which does not allow for a rapid refinement of the model to the investigated scenario. Therefore, model complexity is a bottleneck for the investigation and the development of the reactor technology under study. For a modeller, it is crucial to select the level of complexity that simultaneously will fulfil a required, satisfactory accuracy of a prediction, will be technically possible in implementation and will be feasible in terms of time and cost.

The reactor submodel of a comprehensive biomass conversion model is the most difficult and the most complex part among all model parts, so a short elaboration on its problems is provided here. An increase of the computational demand needed to solve a reactor model, besides the increased complexity of solid phase movement description (e.g. via application of DEM), is caused by expanding the meshed geometry of a reactor domain as well as by an increase in number of particles that have to be considered. Besides high requirement of the hardware computational resources, an additional issue is connected to the application of the DEM method in the solid phase description. A detailed description of solid-phase interactions and mechanical changes of particles is not fully developed yet, so there is no certainty that already established solid-phase descriptions are accurate in their predictions. Another issue that hinders, the effective use of the complex reactor models is the in-depth knowledge on how to use the computational resources in an economical and an effective manner (e.g. parallelisation of computation, adjustment of the procedure of a solver) [5]. From the side of practice, there also exists a problem with the insufficiently developed software, which can have problems with mesh adaptation in more complex scenarios which form a barrier in modelling, like in e.g. modelling a double-screw rotary reactor [160].

\subsection{Conclusions}

Numerical modelling is a very robust tool, which allows for cost-effective research and development of technologies within the field of biomass thermal processing. As it is indicated in this chapter, proper construction and use of a comprehensive model needs knowledge from different areas of science. Only through their combination in an efficient manner, the model will lead to reasonable and useful results.

In theory, there is no limitation to model every processing technology or to base the model on parameters for any range (feedstock or process-related). Nonetheless, from a practical point of view, the selected environment of conversion, as well as the applied processed material, imposes strong boundaries on the modelled system. Those boundaries impose limits on possibilities of the model's validation against experimental data, which is the only reliable method to assess model performance.

The level of complexity and the proper selection of components of the model has a significant influence on the model's accuracy and reliability. A general, descriptive summary of the submodels of a comprehensive biomass conversion model is presented in table 15.16. In general, the balance between accuracy and computational efficiency as well as the technical feasibly have to be obtained. It is advised to apply the most detailed description when it is feasible, and always a check if the model cannot be simplified without loss in model accuracy. This balance has to be taken as one of the priorities in modelling practice. 
Table 15.16 Descriptive summary of components of a comprehensive biomass conversion model

\begin{tabular}{|c|c|c|c|}
\hline Submodel & Molecular & Single Particle & Reactor \\
\hline Used for & $\begin{array}{c}\text { Investigation of } \\
\text { biomass degradation } \\
\text { chemistry depending } \\
\text { on the initial feedstock } \\
\text { composition }\end{array}$ & $\begin{array}{c}\text { Investigation of particles' } \\
\text { thermo-physical and } \\
\text { structural changes and their } \\
\text { influence on the pyrolysis } \\
\text { product yields and } \\
\text { composition }\end{array}$ & $\begin{array}{c}\text { Investigation of the influence of } \\
\text { large-scale production parameters } \\
\text { on the product quality and process } \\
\text { efficiency }\end{array}$ \\
\hline Possible to predict & $\begin{array}{l}\text { Pyrolysis product yields } \\
\text { and composition }\end{array}$ & $\begin{array}{c}\text { Yields and composition of } \\
\text { pyrolysis products, mass loss, } \\
\text { temperature distribution, } \\
\text { pressure distribution, shape } \\
\text { and porosity in single } \\
\text { particles }\end{array}$ & $\begin{array}{c}\text { Product streams and their } \\
\text { composition, size distribution of } \\
\text { solids, mass and heat transfer } \\
\text { distribution in a reactor, production } \\
\text { quality and efficiency }\end{array}$ \\
\hline $\begin{array}{l}\text { Particles size / } \\
\text { Thermal regime }\end{array}$ & $\begin{array}{l}\text { Only fine powders, } \\
\text { which belong to the } \\
\text { kinetic regime, for } \\
\text { other thermal regimes } \\
\text { the influence of } \\
\text { structural and material } \\
\text { thermo-physical factors } \\
\text { will introduce bias }\end{array}$ & $\begin{array}{l}\text { Theoretically applicable to } \\
\text { every size of a given particle } \\
\text { (and associated thermal } \\
\text { regime), in practice it is not } \\
\text { efficient to model kinetic } \\
\text { regime }\end{array}$ & $\begin{array}{c}\text { Applied simplificationdepends on } \\
\text { the particle size (thermal regime): } \\
\text { small particles, kinetic regime - } \\
\text { Eulerian-Eulerian, medium size } \\
\text { particles, thermally thin regime - } \\
\text { Eulerian-Lagrangian (DPM, DDPM), } \\
\text { large particles, thermally thick } \\
\text { regime - Eulerian-Lagrangian } \\
\text { (DEM) }\end{array}$ \\
\hline Complexity & $\begin{array}{l}\text { Simple, only needs } \\
\text { thermodynamic data } \\
\text { for the compounds in } \\
\text { the kinetic scheme }\end{array}$ & $\begin{array}{l}\text { Complex, besides the data for } \\
\text { reaction kinetics, the model } \\
\text { also requires material's } \\
\text { thermo-physical and } \\
\text { structural information and } \\
\text { their changes with conversion }\end{array}$ & $\begin{array}{l}\text { The most complex, requires data of } \\
\text { molecular and single particle model } \\
\text { as well as data of particle-wall, } \\
\text { particle-particle and particle- } \\
\text { reactor gas interactions }\end{array}$ \\
\hline $\begin{array}{l}\text { Computational } \\
\text { burden }\end{array}$ & $\begin{array}{l}\text { Low, numerical solver } \\
\text { depends on the } \\
\text { complexity of the } \\
\text { applied kinetic scheme }\end{array}$ & $\begin{array}{l}\text { Medium, numerical solyer is } \\
\text { needed, depends on the } \\
\text { complexity of the molecular } \\
\text { model, the structure- } \\
\text { chemistry interconnections } \\
\text { and thermo-physical changes }\end{array}$ & $\begin{array}{l}\text { High, robust numerical solver } \\
\text { essential, depends on the single } \\
\text { particle model complexity, number } \\
\text { of modelled particles and applied } \\
\text { simplifications }\end{array}$ \\
\hline $\begin{array}{l}\text { Knowledge-gap to } \\
\text { fill urgently }\end{array}$ & $\begin{array}{l}\text { Quantitative influence } \\
\text { of the mineral matter } \\
\text { and heating rate on the } \\
\text { degradation } \\
\text { mechanism }\end{array}$ & $\begin{array}{l}\text { The link between pore size } \\
\text { distribution, gas permeability } \\
\text { and extent of conversion; a } \\
\text { reliable model of solid } \\
\text { thermal conductivity }\end{array}$ & $\begin{array}{l}\text { A detailed description of the } \\
\text { mechanical behaviour of particles } \\
\text { and their interactions }\end{array}$ \\
\hline
\end{tabular}

Work made within the Greencarbon Project, which has received funding from the European Union's Horizon 2020 research and innovation programme under the Marie Skłodowska-Curie grant agreement No 721991.

\section{References}

1. Antal M), Grønly M (2003) The Art, Science, and Technology of Charcoal Production. Industrial \& Engineering Chemistry Research 42 (8):1619-1640. doi:10.1021/ie0207919

1439 2. Dubois G (2018) Modeling and simulation: challenges and best practices for industry. CRC Press, Boca Raton. doi:https://doi.org/10.1201/9781351241137

1442 9-12 Dec. 1990 1990. pp 25-32. doi:10.1109/WSC.1990.129482

1443 4. Kennedy MC, O'Hagan A (2001) Bayesian calibration of computer models. Journal of the Royal Statistical 1444 Society: Series B (Statistical Methodology) 63 (3):425-464. doi:doi:10.1111/1467-9868.00294 
5. Anca-Couce A (2016) Reaction mechanisms and multi-scale modelling of lignocellulosic biomass pyrolysis. Progress in Energy and Combustion Science 53:41-79. doi:https://doi.org/10.1016/i.pecs.2015.10.002

6. Debiagi PEA, Pecchi C, Gentile G, Frassoldati A, Cuoci A, Faravelli T, Ranzi E (2015) Extractives Extend the Applicability of Multistep Kinetic Scheme of Biomass Pyrolysis. Energy \& Fuels 29 (10):6544-6555. doi:10.1021/acs.energyfuels.5b01753

1450

1451

1452

1453

1454

1455

1456

1457

1458

1459

1460

1461

1462

1463

1464

1465

1466

1467

1468

1469

1470

1471

7. Vassilev SV, Baxter D, Andersen LK, Vassileva CG (2010) An overview of the chemical composition of biomass. Fuel 89 (5):913-933. doi:https://doi.org/10.1016/i.fuel.2009.10.022

8. Vassilev SV, Baxter D, Andersen LK, Vassileva CG, Morgan TJ (2012) An overview of the organic and inorganic phase composition of biomass. Fuel 94:1-33. doi:https://doi.org/10.1016/i.fuel.2011.09.030

9. Vassilev SV, Baxter D, Andersen LK, Vassileva CG (2013) An overview of the composition and application of biomass ash. Part 1. Phase-mineral and chemical composition and classification. Fuel 105:40-76. doi:https://doi.org/10.1016/i.fuel.2012.09.041

10. Vassilev SV, Baxter D, Andersen LK, Vassileva CG (2013) An overview of the composition and application of biomass ash.: Part 2. Potential utilisation, technological and ecological advantages and challenges. Fuel 105:19-39. doi:https://doi.org/10.1016/i.fuel.2012.10.001

11. Mamleev V, Bourbigot S, Le Bras M, Yvon J (2009) The facts and hypotheses relating to the phenomenological model of cellulose pyrolysis: Interdependence of the steps. Journal of Analytical and Applied Pyrolysis 84 (1):1-17. doi:https://doi.org/10.1016/i.jaap.2008.10.014

12. Thy P, Yu C, Jenkins BM, Lesher CE (2013) Inorganic Composition and Environmental Impact of Biomass Feedstock. Energy \& Fuels 27 (7):3969-3987. doi:10.1021/ef400660u

13. Ronsse F, van Hecke S, Dickinson D, Prins W (2012) Production and characterization of slow pyrolysis biochar: influence of feedstock type and pyrolysis conditions. GGB Bioenergy 5 (2):104-115. doi:10.1111/gcbb.12018

14. Ronsse F, Bai X, Prins W, Brown RC (2012) Secondary reactions of levoglucosan and char in the fast pyrolysis of cellulose. Environmental Progress \& Sustainable Energy 31 (2):256-260. doi:10.1002/ep.11633

1472

1473

1474

1475

1476

1477

1478

1479

1480

1481

1482

1483

1484

1485

1486

1487

1488

1489

1490

1491

1492

1493

1494

1495

1496

1497

1498

15. Patwardhan PR, Brown RC, Shanks BH (2011) Product Dístribution from the Fast Pyrolysis of Hemicellulose. ChemSusChem 4 (5):636-643. doi:10.1002/cssc.201000425

16. Faravelli T, Frassoldati A, Migliavacca G, Ranzi E (2010) Detailed kinetic modeling of the thermal degradation of lignins. Biomass and Bioenergy 34 (3):290-301. doi:https://doi.org/10.1016/i.biombioe.2009.101018,

17. Nowakowska M, Herbinet O, Dufour A, Glaude P-A (2014) Detailed kinetic study of anisole pyrolysis and oxidation to understand tar formation during biomass combustion and gasification. Combustion and Flame 161 (6):1474-1488. doi:https://doi.org/10.1016/i.eombustflame.2013.11.024

18. Zheng M, Wang Z, Li X, Qiao X, Song W, Guo L (2016) Initial reaction mechanisms of cellulose pyrolysis revealed by ReaxFF molecular dynamics. Fuel 177:130-141. doi:https://doi.org/10.1016/i.fuel.2016.03.008

19. Anca-Couce A, Mehrabian R, Scharler R, Obernberger I (2014) Kinetic scheme of biomass pyrolysis considering secondary charring reactions. Energy Conversion and Management 87:687-696. doi:https://doi.org/10.1016/j.enconman.2014.07.061

20. Yang H, Yan R, Chen H, Lee DH, Zheng C (2007) Characteristics of hemicellulose, cellulose and lignin pyrolysis. Fuel 86 (12-13):1781-1788. doi:http://dx.doi.org/10.1016/i.fuel.2006.12.013

21. Wu S, Shen D, HuJ, Zhang H, Xiao R (2016) Cellulose-lignin interactions during fast pyrolysis with different temperatures and mixing methods. Biomass and Bioenergy 90:209-217. doi:https://doiorg/10.1016/j.biombioe.2016.04.012

22. Nowakowski DJ, Bridgwater AV, Elliott DC, Meier D, de Wild P (2010) Lignin fast pyrolysis: Results from an international collaboration. Journal of Analytical and Applied Pyrolysis 88 (1):53-72. doi:https./Adoi.org/10.1016/j.jaap.2010.02.009

23. Vyazovkin S, Chrissafis K, Di Lorenzo ML, Koga N, Pijolat M, Roduit B, Sbirrazzuoli N, Suñol JJ (2014) ICTAC Kinetics Committee recommendations for collecting experimental thermal analysis data for kinetic computations. Thermochimica Acta 590:1-23. doi:https://doi.org/10.1016/i.tca.2014.05.036

24. Di Blasi C (2008) Modeling chemical and physical processes of wood and biomass pyrolysis. Progress in Energy and Combustion Science 34 (1):47-90. doi:https://doi.org/10.1016/i.pecs.2006.12.001

1499

1500

1501

1502

1503 25. Liden AG, Berruti F, Scott DS (1988) A kinetic model for the production of liquids from flash pyrolysis of biomass. Chemical Engineering Communications 65 (1):207-221. doi:10.1080/00986448808940254 26. Shafizadeh F, Chin PPS (1977) Thermal Deterioration of Wood. In: Wood Technology: Chemical Aspects, vol 43. ACS Symposium Series, vol 43. American Chemical Society, pp 57-81. doi:doi:10.1021/bk-19770043.ch005 
1504

1505

1506

1507

1508

1509

1510

1511

1512

1513

1514

1515

1516

1517

1518

1519

1520

1521

1522

1523

1524

1525

1526

1527

1528

1529

1530

1531

1532

1533

1534

1535

1536

1537

1538

1539

1540

1541

1542

1543

1544

1545

1546

1547

1548

1549

1550

1551

1552

1553

1554

1555

1556

1557

1558

1559

1560

1561

1562

27. Anca-Couce A, Berger A, Zobel N (2014) How to determine consistent biomass pyrolysis kinetics in a parallel reaction scheme. Fuel 123:230-240. doi:https://doi.org/10.1016/i.fuel.2014.01.014 28. Park WC, Atreya A, Baum HR (2010) Experimental and theoretical investigation of heat and mass transfer processes during wood pyrolysis. Combustion and Flame 157 doi:https://doi.org/10.1016/j.combustflame.2009.10.006 29. Koufopanos CA, Lucchesi A, Maschio G (1989) Kinetic modelling of the pyrolysis of biomass and biomass $\begin{array}{llllll}\text { components. The Canadian Journal of Chemical Engineering } 67 & \text { (1):75-84. }\end{array}$ doi:doi:10.1002/cjce.5450670111

30. Ranzi E, Cuoci A, Faravelli T, Frassoldati A, Migliavacca G, Pierucci S, Sommariva S (2008) Chemical Kinetics of Biomass Pyrolysis. Energy \& Fuels 22 (6):4292-4300. doi:10.1021/ef800551t

31. Cuoci A FT, Frassoldati A, Granata S, Migliavacca G, Ranzi E, A general mathematical model of biomass devolatilization. Note 1. Lumped kinetic models of cellulose, hemicellulose and lignin, In: Proceedings of the 30th combustion meeting of the Italian Section of the Combustion Institute VI,,2007. pp 2.1-2.6

32. Cuoci A FT, Frassoldati A, Granata S, Migliavacca G, Pierucci S, (2007) A general mathematical model of biomass devolatilization. Note 2. Detailed kinetics of volatile species, . Proceedings of the 30 th combustion meeting of the Italian Section of the Combustion Institute VI,:3.1-3.6

33. Corbetta M, Frassoldati A, Bennadji H, Smith K, Serapiglia MJ, Gauthier G, Melkior T, Ranzi E, Fisher EM (2014) Pyrolysis of Centimeter-Scale Woody Biomass Particles: Kinetic Modeling and Experimental Validation. Energy \& Fuels 28 (6):3884-3898. doi:10.1021/ef500525v

34. Ranzi E, Debiagi PEA, Frassoldati A (2017) Mathematical Modeling of Fast Biomass Pyrolysis and BioOil Formation. Note I: Kinetic Mechanism of Biomass Pyrolysis. ACS Sustainable Chemistry \& Engineering 5 (4):2867-2881. doi:10.1021/acssuschemeng.6b03096

35. Ranzi E, Debiagi PEA, Frassoldati A (2017) Mathematical Modeling of Fast Biomass Pyrolysis and BioOil Formation. Note II: Secondary Gas-Phase Reactions and Bio-Oil Formation. ACS Sustainable Chemistry \& Engineering 5 (4):2882-2896. doi:10.1021/acssuschemeng.6b03098

36. Debiagi P, Gentile G, Cuoci A, Frassoldati A, Ranzi E, Faravelli T (2018) A predictive model of biochar formation and characterization. Journal of Analytical and Applied Pyrolysis 134:326-335. doi:https://doi.org/10.1016/j.jaap.2018.06.022

37. Anca-Couce A, Scharler R (2017) Modelling heat of reaction in biomass pyrolysis with detailed reaction schemes. Fuel 206:572-579. doi:https://doi.org/10.1016/i.fuel.2017.06.011

38. Anca-Couce A, Obernberger I (2016) Application of a detailed biomass pyrolysis kinetic scheme to hardwood and softwood torrefaction. Fuel 167:158-167. doi:https://doi.org/10.1016/i.fuel.2015.11.062 39. Rath J, Wolfinger MG, Steiner G, Krammer G, Barontini F, Cozzani V (2003) Heat of wood pyrolysis. Fuel 82 (1):81-91. doi:https://doi.org/10.1016/S0016-2361(02)00138-2

40. Blondeau J, Jeanmart H (2012) Biomass pyrolysis at high temperatures: Prediction of gaseous species yields from an anisotropic particle. Biomass and Bioenergy 41:107-121. doi:https://doi.org/10.1016/j.biombioe.2012.02.016

41. Mellin P, Kantarelis E, Yang W (2014) Computational fluid dynamics modeling of biomass fast pyrolysis in a fluidized bed reactor, using a comprehensive chemistry scheme. Fuel 117:704-715. doi:https://doi.org/10.1016/i.fül.2013.09.009

42. Anca-Couce A, Sommersacher P, Scharler R (2017) Online experiments and modelling with a detailed reaction scheme of single particle biomass pyrolysis. Journal of Analytical and Applied Pyrolysis 127:411425. doi:https://doi.org/101016/i.jaap.2017.07.008

43. Norinaga K, Shoji T, Kudo S, Hayashi J-i (2013) Detailed chemical kinetic modelling of vapour-phase cracking of multi-component molecular mixtures derived from the fast pyrolysis of cellulose. Fuel 103:141150. doi:https://doi.org/10/1016/j.fuel.2011.07.045

44. Trendewiez A, Evans R, Dutta A, Sykes R, Carpenter D, Braun R (2015) Evaluating the effect of potassium on cellulose pyrolysis reaction kinetics. Biomass and Bioenergy 74:15-25. doi:https.//droi.org/10.1016/j.biombioe.2015.01.001

45. Versteeg HK, Malalasekera W (2011) An introduction to computational fluid dynamics: the finite volume method. Pearson Education, Harlow

46. Tu J, Yeoh GH, Liu C (2018) Computational fluid dynamics: a practical approach. Oxford Elsevier, Butterworth-Heinemann,

47. Childress S (2009) An introduction to theoretical fluid mechanics. AMS and the Courant Institute of Mathematical Sciences, New York

48. Batchelor GK (2013) An introduction to fluid dynamics. Cambridge University Press, Cambridge

49. Whitaker S (1977) Simultaneous Heat, Mass, and Momentum Transfer in Porous Media: A Theory of Drying. In: Hartnett JP, Irvine TF (eds) Advances in Heat Transfer, vol 13. Elsevier, pp 119-203. doi:https://doi.org/10.1016/S0065-2717(08)70223-5 

computational model for simulating the drying of porous media. International Journal of Heat and Mas Transfer 42 (24):4501-4521. doi:https://doi.org/10.1016/S0017-9310(99)00098-8 51. Nasrallah SB, Perre P (1988) Detailed study of a model of heat and mass transfer during convective drying of porous media. International Journal of Heat and Mass Transfer 31 (5):957-967. doi:https://doi.org/10.1016/0017-9310(88)90084-1

52. Grønli MG (1996) A theoretical and experimental study of thermal degradation of biomass (PhD Thesis). NTNU, Trondheim

53. Gentile G, Debiagi PEA, Cuoci A, Frassoldati A, Ranzi E, Faravelli T (2017) A computational framework for the pyrolysis of anisotropic biomass particles. Chemical Engineering Journal 321:458-473. doi:https://doi.org/10.1016/i.cej.2017.03.113

54. Jalili M, Anca-Couce A, Zobel N (2013) On the Uncertainty of a Mathematical Model for Drying of a Wood Particle. Energy \& Fuels 27 (11):6705-6717. doi:10.1021/ef401156s

55. Melaaen MC (1996) Numerical analysis of heat and mass transfer in drying and pyrolysis of porous media. Numerical Heat Transfer, Part A: Applications 29 (4):331-355. doi:10.1080/10407789608913796 56. Anca-Couce A, Zobel N (2012) Numerical analysis of a biomass pyrolysis particle model: Solution method optimized for the coupling to reactor models. Fuel 97:80-88. doi:https://doi.org/10.1016/i.fuel.2012.02.033

57. Fatehi H, Bai XS (2014) A Comprehensive Mathematical Model for Biomass Combustion. Combustion Science and Technology 186 (4-5):574-593. doi:10.1080/00102202.2014.883255

58. Shi X (2017) Computational fluid dynamics modelling of biomass slow pyrolysis in screw reactors for the production of biochar and charcoal. Ghent University, Gent,

59. Chan W-CR, Kelbon M, Krieger BB (1985) Modelling and experimental verification of physical and chemical processes during pyrolysis of a large biomass particle. Fuel 64 (11):1505-1513. doi:https://doi.org/10.1016/0016-2361(85)90364-3

60. Shrestha D, Cramer S, White R (1994) Time-temperature profile across a lumber section exposed to pyrolytic temperatures. Fire and Materials 18 (4):211-220. doi:10.1002/fam.810180404

61. Bryden KM, Hagge MJ (2003) Modeling the combined impact of moisture and char shrinkage on the pyrolysis of a biomass particle次. Fuel 82 (13):1633-1644. doi:https://doi.org/10.1016/S00162361(03)00108-X

62. Di Blasi CD, Branca C, Sparano S, La Mantia B (2003) Drying characteristics of wood cylinders for conditions pertinent to fixed-bed countercurrent gasification. Biomass and Bioenergy 25 (1):45-58. doi:https://doi.org/10.1016/S0961-9534(02)00180-

63. Peters B, Bruch C (2003) Drying and pyrolysis of wood particles: experiments and simulation. Journal of Analytical and Applied Pyrolysis 70 (2):233-250. doi:https://doi.org/10.1016/S0165-2370(02)00134-1 64. Haberle I, Haugen NEL, Skreiberg $\emptyset$ (2017) Drying of Thermally Thick Wood Particles: A Study of the Numerical Efficiency, Accuracy, and Stability of Common Drying Models. Energy \& Fuels 31 (12):1374313760. doi:10.1021/acs.energyfuels.7b02771

65. Lu H, Robert W, Peirce G, Ripa B, Baxter LL (2008) Comprehensive Study of Biomass Particle Combustion. Energy \& Fuels 22 (4):2826-2839. doi:10.1021/ef800006z

66. Thunman H, Leckner B, Niklasson F, Johnsson F (2002) Combustion of wood particles-a particle model for eulerian calculations. Combustion and Flame 129 (1):30-46. doi:https://doi.org/10.1016/S00102180(01)00371-6

67. Raznjevic K (1976) Handbook of thermodynamic tables and charts. Hemisphere Pub. Corp., Washington 68. Gouverment US (2017) The encyclopedia of wood. EPBM, Brattleboro, Vermont

69. Olek W, Perré P, Weres J (2005) Inverse analysis of the transient bound water diffusion in wood. Holzforschung, vol 59. doi:10.1515/HF.2005.007

70. Moghtaderi B, Dlugogorski BZ, Kennedy EM, Fletcher DF (1999) Effects of the structural properties of solid fuels on their re-ignition characteristics. Fire and Materials 22 (4):155-165. doi:10.1002/(SICI)10991018(1998070)22:4<155::AID-FAM651>3.0.CO;2-F

71. Di Blasi C (1998) Multi-phase moisture transfer in the high-temperature drying of wood particles. Chemical Engineering Science 53 (2):353-366. doi:https://doi.org/10.1016/S0009-2509(97)00197-8

72. Stanish MA, Schajer GS, Kayihan F (1986) A mathematical model of drying for hygroscopic porous media. AIChE Journal 32 (8):1301-1311. doi:10.1002/aic.690320808

73. Lehmann J (2017) Biochar - a guide to analytical methods.

74. Plötze M, Niemz P (2011) Porosity and pore size distribution of different wood types as determined by mercury intrusion porosimetry. European Journal of Wood and Wood Products 69 (4):649-657. doi:10.1007/s00107-010-0504-0 

K, Davies CA (2014) New approaches to measuring biochar density and porosity. Biomass and Bioenergy 66:176-185. doi:https://doi.org/10.1016/j.biombioe.2014.03.059

76. Zauer M, Pfriem A, Wagenführ A (2013) Toward improved understanding of the cell-wall density and porosity of wood determined by gas pycnometry. Wood Science and Technology 47 (6):1197-1211. doi:10.1007/s00226-013-0568-1 synthetic wood chars for use as surrogates for natural sorbents. Organic Geochemistry 37 (3):321-333. doi:https://doi.org/10.1016/j.orggeochem.2005.10.008

78. Emmett PH (1948) Adsorption and Pore-Size Measurements on Charcoals and Whetlerites. Chemical Reviews 43 (1):69-148. doi:10.1021/cr60134a003

79. Zelinka SL, Glass SV, Jakes JE, Stone DS (2016) A solution thermodynamics definition of the fiber saturation point and the derivation of a wood-water phase (state) diagram. Wood Science and Technology 50 (3):443-462. doi:10.1007/s00226-015-0788-7

80. Gezici-Koç Ö, Erich SJF, Huinink HP, van der Ven LGJ, Adan OCG (2017) Bound añd free water distribution in wood during water uptake and drying as measured by $1 \mathrm{D}$ magnetic resonance imaging. Cellulose 24 (2):535-553. doi:10.1007/s10570-016-1173-x

81. Stamm AJ (1971) Review of nine methods for determining the fiber saturation points of wood and wood products. Wood Sci 4:114-128

82. Skaar C (1988) Wood-water relations. Springer-verlag, Belin

83. Stamm AJ, Seborg RM (1934) Absorption compression on cellulose and wood: I Density measurements in benzene. . J Phys Chem 39:133-142

84. Siau JF (1984) Transport processes in wood. Springer-Verlag, Berlin; New York

85. Spolek GA, Plumb OA (1981) Capillary pressure in softwoods. Wøod Science and Technology 15 (3):189199. doi:10.1007/BF00353471

86. Perre P, Degiovanni A (1990) Simulation par volumes finis des transferts couplés en milieux poreux anisotropes: séchage du bois à basse et à haute température. International Journal of Heat and Mass Transfer 33 (11):2463-2478. doi:https://doi.org/10.1016/0017-9310(90)90004-E

87. Lee CK, Chaiken RF, Singer JM (1977) Charring pyrolysis of wood in fires by laser simulation. Symposium (International) on Combustion 16 (1):1459-1470. doi:https./Vdoi.org/10.1016/S0082-0784(77)80428-1 88. Comstock GL (1970) Directional permeability of softwoods. Wood Fiber 1:283-289

89. Perre P (1987) Measurements of softwoods'permeability to air: Importance upon the drying model. International Communications in Heat and Mass Transfer 14 (5):519-529. doi:https://doi.org/10.1016/0735-1933(87)900

90. Turner IW, Perré P (2004) Vacuum drying of wood with radiative heating: II. Comparison between theory and experiment. AIChE Journal 50 (1):108-118. doi:10.1002/aic.10010

91. Di Blasi C (1996) Heat, momentum and mass transport through a shrinking biomass particle exposed to thermal radiation. Chemical Engineering Science 51 (7):1121-1132. doi:https://doi.org/10.1016/S0009$\underline{2509(96) 80011-X}$

92. Di Blasi C (2000) Modelling the fast pyrolysis of cellulosic particles in fluid-bed reactors. Chemical Engineering Science 55 (24):5999-6013. doi:https://doi.org/10.1016/S0009-2509(00)00406-1

93. Larfeldt J, Lecher B, Melaaen MC (2000) Modelling and Measurements of Drying and Pyrolysis of Large Wood Particles. In: Progress in Thermochemical Biomass Conversion. doi:doi:10.1002/9780470694954.ch85

94. Ronewicz K, Kluska J, Heda Ł, Kardaś D (2017) Chemical and Physical Properties of Pine Wood during Pyrolysis. Drvna industrija 68 (1):29-36. doi:https://doi.org/10.5552/drind.2017.1617

95. Perré P, Turner IW (2006) A dual-scale model for describing drier and porous medium interactions. AIChE Journal 52 (9):3109-3117. doi:10.1002/aic.10918

96. Couture FJomaa W, Puiggali JR (1996) Relative permeability relations: A key factor for a drying model. Transport in Porous Media 23 (3):303-335. doi:10.1007/BF00167101

97. Perre P, Moser M, Martin M (1993) Advances in transport phenomena during convective drying with superheated steam and moist air. International Journal of Heat and Mass Transfer 36 (11):2725-2746. doi:https:/dolorg/10.1016/0017-9310(93)90093-L

98. Perre P, Turner I (2001) Determination of the Material Property Variations Across the Growth Ring of Softwood for Use in a Heterogeneous Drying Model. Part 2. Use of Homogenisation to Predict Bound Liquid Diffusivity and Thermal Conductivity. Holzforschung, vol 55. doi:10.1515/HF.2001.069

99. Stamm AJ (1964) Wood and cellulose science. Ronald Press Co., New York 
100. Perré P, Turner I (2001) Determination of the Material Property Variations Across the Growth Ring of Softwood for Use in a Heterogeneous Drying Model Part 1. Capillary Pressure,Tracheid Model and Absolute

1680 Permeability. Holzforschung, vol 55. doi:10.1515/HF.2001.052

1681

1682

1683

1684

1685

1686

1687

1688

1689

1690

1691

1692

1693

1694

1695

1696

1697

1698

1699

1700

1701

1702

1703

1704

1705

1706

1707

1708

1709

1710

1711

1712

1713

1714

1715

1716

1717

1718

1719

1720

1721

1722

1723

1724

1725

1726

1727

1728

1729

1730

1731

1732

1733

1734

1735

101. Bird RB, Stewart WE, Lightfoot EN (2002) Transport phenomena. Wiley, New York

102. Poling BE, Prausnitz JM, O'Connell JP (2007) The properties of gases and liquids. McGraw-Hill, Bogotá 103. Atreya A, Olszewski P, Chen Y, Baum HR (2017) The effect of size, shape and pyrolysis conditions on the thermal decomposition of wood particles and firebrands. International Journal of Heat and Mass Transfer 107:319-328. doi:https://doi.org/10.1016/j.ijheatmasstransfer.2016.11.051

104. Janse AMC, Westerhout RWJ, Prins W (2000) Modelling of flash pyrolysis of a single wood particle. Chemical Engineering and Processing: Process Intensification 39 (3):239-252. doi:https://doi.org/10.1016/S0255-2701(99)00092-6

105. Bruggeman DAG (1935) Berechnung verschiedener physikalischer Konstanten von heterogenen Substanzen. I. Dielektrizitätskonstanten und Leitfähigkeiten der Mischkörper aus isotropen Substanzen. Annalen der Physik 416 (7):636-664. doi:10.1002/andp.19354160705

106. Millington RJ, Quirk JP (1961) Permeability of porous solids. Transactions of the Faraday Society 57 (0):1200-1207. doi:10.1039/TF9615701200

107. Stanish MA (1986) The roles of bound water chemical potential and gas phase diffusion in moisture transport through wood. Wood Science and Technology 20 (1):53-70. doi:10.1007/BF00350694

108. Bonneau P, Puiggali JR (1993) Influence of heartwood-sapwood proportions on the drying kinetics of a board. Wood Science and Technology 28 (1):67-85. doi:10.1007/BF00193878

109. Fernandez ML, Howell JR (1997) CONVECTWE DRYING MODEL OF SOUTHERN PINE. Drying Technology 15 (10):2343-2375. doi:10.1080/07373939708917365

110. Dupont C, Chiriac R, Gauthier G, Toche F (2014) Heat capacity measurements of various biomass types and pyrolysis residues. Fuel 115:644-651. doi:https://doi.org/10.1016/. fuel.2013.07.086

111. Gorensek MB, Shukre R, Chen C-C (2019) Development of a Thermophysical Properties Model for Flowsheet Simulation of Biomass Pyrolysis Processes. ACS Sustainable Chemistry \& Engineering 7 (9):9017-9027. doi:10.1021/acssuschemeng.9b01278

112. Hunt JFG, H. Lebow, P., (2008) Theoretical thermal conductivity equation for uniform density wood cells. Wood and Fiber Science 40 (2):167-180

113. NIST Chemistry WebBook (2018,) https://webbook.nistgov/chemistry/.

114. McBride BJ, Gordon S, Lewis Research C (1996) Computer program for calculation of complex chemical equilibrium compositions and applications. II, II. National Aeronautics and Space Administration, Office of Management, Scientific and Technical Information Program, [Washington, DC]

115. Davidson TA, USA Bureau of Mines (1993) A simple and accurate method for calculating viscosity of gaseous mixtures.

116. de Paiva Souza MEN, S. A. (2000) Heat and Mass Transfer Model in Wood Chip Drying, . Wood ond Fiber Scrence 32:153-163

117. Williams CL, Westover TL, Petkovic LM, Matthews AC, Stevens DM, Nelson KR (2017) Determining Thermal Transport Properties for Softwoods Under Pyrolysis Conditions. ACS Sustainable Chemistry \& Engineering 5 (1):1019-1025. doi:10.1021/acssuschemeng.6b02326

118. Rumble JR, Lide DR, Bruno TJ (2018) CRC handbook of chemistry and physics: a ready-reference book of chemical and physical data.

119. Maku T (1954) Studies on the heat conduction in wood, . Wood Research Bulletin, JapanWood Research Institute, Kyoto University, Kyoto 13

120. Suleiman BM, Larfeldt b Leckner B, Gustavsson M (1999) Thermal conductivity and diffusivity of wood. Wood Science and Technology 33 (6):465-473. doi:10.1007/s002260050130

121. Behazin E (2016) Mechanical, chemical and physical properities of wood and perennial grass biochars for possible composite aplication., . BioResources 11 (1):1334-1348

122. Yaws CL (1995) Handbook of transport property data : viscosity, thermal conductivity, and diffusion coefficients of liquids and gases. Gulf Pub. Co., Houston, Tex.

123. Vargaftik NB (1994) Handbook of thermal conductivity of liquids and gases. CRC Press, Boca Raton 124. Zaitseva LS, Yakush LV, Vanicheva NA (1976) Thermal conductivities of benzene and toluene vapors. Journal of engineering physics 31 (5):1292-1295. doi:10.1007/BF00859307

125. Panton RL, Rittmann JG (1971) Pyrolysis of a slab of porous material. Symposium (International) on Combustion 13 (1):881-891. doi:https://doi.org/10.1016/S0082-0784(71)80089-9

126. Olek W, Weres J, Guzenda R (2003) Effects of Thermal Conductivity Data on Accuracy of Modeling Heat Transfer in Wood. Holzforschung, vol 57. doi:10.1515/HF.2003.047

127. Thunman H, Leckner B (2002) Thermal conductivity of wood-models for different stages of

1736 combustion. Biomass and Bioenergy 23 (1):47-54. doi:https://doi.org/10.1016/S0961-9534(02)00031-4 
128. Kollmann FFP, Côté WA (1968) Principles of Wood Science and Technology: I Solid Wood. 129. Caposciutti G, Almuina-Villar H, Dieguez-Alonso A, Gruber T, Kelz J, Desideri U, Hochenauer C, Scharle $\mathrm{R}$, Anca-Couce A (2019) Experimental investigation on biomass shrinking and swelling behaviour: Particles pyrolysis and wood logs combustion. Biomass and Bioenergy 123:1-13 doi:https://doi.org/10.1016/j.biombioe.2019.01.044 130. Bellais M (2007) Modelling of the pyrolysis of large wood particles. Kungliga Tekniska högskolan, Stockholm 131. P. P (1999) How to get a relevant material model for wood drying simulation? Advances in drying of wood COST Action E 15

132. Pattanotai T, Watanabe H, Okazaki K (2014) Gasification characteristic of large wood chars with anisotropic structure. Fuel 117:331-339. doi:https://doi.org/10.1016/i.fuel.2013.09.030 133. Davidsson KO, Pettersson JBC (2002) Birch wood particle shrinkage during rapid pyrolysis. Fuel 81 (3):263-270. doi:https://doi.org/10.1016/S0016-2361(01)00169-7

134. Çengel YA, Ghajar AJ, Kanoglu M (2016) Heat and mass transfer : fundamentals \& applications. 135. Botterill JSM (1970) Heat transfer to gas-fluidized beds. Powder Technology 4 (1):19-26. doi:https://doi.org/10.1016/0032-5910(70)80003-1 136. Holman JP (2001) Heat transfer (metric version). McGraw-Hill, Boston 137. Di Natale F, Lancia A, Nigro R (2007) Surface-to-bed heat transfer in fluidised beds: Effect of surface shape. Powder Technology 174 (3):75-81. doi:https://doi.org/10.1016/j.powtec.2007.01.010 138. Di Natale F, Lancia A, Nigro R (2008) A single particle model for surface-to-bed heat transfer in fluidized beds. Powder Technology 187 (1):68-78. doi:https://doi.org/10.1016/ipowtec.2008.01.014 139. Di Natale F, Nigro R (2012) A critical comparison between local heat and mass transfer coefficients of horizontal cylinders immersed in bubbling fluidised beds. International Joumal of Heat and Mass Transfer 55 (25):8178-8183. doi:https://doi.org/10.1016/j.ijheatmasstrans fer.2012.08.002

140. Prins W (1987) Fluidized bed combustion of a single carbon particle. University of Twente, Enschede 141. Babu BV, Chaurasia AS (2004) Pyrolysis of biomass: improved models for simultaneous kinetics and transport of heat, mass and momentum. Energy Conversion and Management 45 (9):1297-1327. doi:https://doi.org/10.1016/j.enconman.2003.09.01

142. Schröder E, Class A, Krebs L (2006) Measurements of heat transfer between particles and gas in packed beds at low to medium Reynolds numbers. Experimental Thermal and Fluid Science 30 (6):545-558. doi:https://doi.org/10.1016/j.expthermflusci.2005.1

143. Kersten SRA, Wang X, Prins W, van Swaaij WPM (2005) Biomass Pyrolysis in a Fluidized Bed Reactor. Part 1: Literature Review and Model Símulations. Industrial \& Engineering Chemistry Research 44 (23):8773-8785. doi:10.1021/ie0504856

144. Sakai M (2016) How Should the Discrete Element Method Be Applied in Industrial Systems?: A Review. KONA Powder and Particle Journal 33:169-178. doi:10.14356/kona.2016023

145. Kloss C, Goniva C, Aichinger G, Pirker S Comprehensive DEM-DPM-CFD Simulations-Model Synthesis, Experimental Validation and Scalability. In: 7th International Conference on CFD in the Minerals and Process Industries, Melbourne, Australia, 2009. pp 1-7

146. Mettler MS, Mushrif SH, Paulsen AD, Javadekar AD, Vlachos DG, Dauenhauer PJ (2012) Revealing pyrolysis chemistry for biofuels production: Conversion of cellulose to furans and small oxygenates. Energy \& Environmental Science 5 (1):5414-5424. doi:10.1039/C1EE02743C

147. Paulsen AD, Mettler MS, Dauenhauer PJ (2013) The Role of Sample Dimension and Temperature in Cellulose Pyrolysis, Energy \& Fuels 27 (4):2126-2134. doi:10.1021/ef302117j 148. Pyle DL, Zaror CA (1984) Heat transfer and kinetics in the low temperature pyrolysis of solids. Chemical Engineering Science 39 (1):147-158. doi:https://doi.org/10.1016/0009-2509(84)80140-2 149. Mehrabian R, Zahirovic S, Scharler R, Obernberger I, Kleditzsch S, Wirtz S, Scherer V, Lu H, Baxter LL (2012) A CFD model for thermal conversion of thermally thick biomass particles. Fuel Processing Technology 95:96-108. doi:https://doi.org/10.1016/i.fuproc.2011.11.021

150. Villermaux J, Antoine B, Lede J, Soulignac F (1986) A new model for thermal volatilization of solid particles undergoing fast pyrolysis. Chemical Engineering Science 41 (1):151-157. doi:https://doilorg/10.1016/0009-2509(86)85208-3

151. Wurzenberger JC, Wallner S, Raupenstrauch H, Khinast JG (2004) Thermal conversion of biomass: Comprehensive reactor and particle modeling. AIChE Journal 48 (10):2398-2411. doi:10.1002/aic.690481029

152. Mahmoudi AH, Hoffmann F, Peters B (2014) Detailed numerical modeling of pyrolysis in a heterogeneous packed bed using XDEM. Journal of Analytical and Applied Pyrolysis 106:9-20. doi:https://doi.org/10.1016/i.jaap.2013.12.001 
153. Anca-Couce A, Zobel N, Jakobsen HA (2013) Multi-scale modeling of fixed-bed thermo-chemical processes of biomass with the representative particle model: Application to pyrolysis. Fuel 103:773-782 doi:https://doi.org/10.1016/i.fuel.2012.05.063 154. Xiong Q, Yang Y, Xu F, Pan Y, Zhang J, Hong K, Lorenzini G, Wang S (2017) Overview of Computational Fluid Dynamics Simulation of Reactor-Scale Biomass Pyrolysis. ACS Sustainable Chemistry \& Engineering 5 (4):2783-2798. doi:10.1021/acssuschemeng.6b02634 155. Subramaniam S (2013) Lagrangian-Eulerian methods for multiphase flows. Progress in Energy and Combustion Science 39 (2):215-245. doi:https://doi.org/10.1016/i.pecs.2012.10.003 156. Ku X, Li T, Løvås T (2013) Influence of drag force correlations on periodic fluidization behavior in Eulerian-Lagrangian simulation of a bubbling fluidized bed. Chemical Engineering Science 95:94-106. doi:https://doi.org/10.1016/i.ces.2013.03.038 157. Ku X, Li T, Løvås T (2015) CFD-DEM simulation of biomass gasification with steam in a fluidized bed reactor. Chemical Engineering Science 122:270-283. doi:https://doi.org/10.1016/i.ces.2014.08.045

158. Xie J, Zhong W, Jin B, Shao Y, Huang Y (2013) Eulerian-Lagrangian method for three-dimensional simulation of fluidized bed coal gasification. Advanced Powder Technology 24 (1):382-392. doi:https://doi.org/10.1016/j.apt.2012.09.001 159. Funke A, Grandl R, Ernst M, Dahmen N (2018) Modelling and improvement of heat transfer coefficient in auger type reactors for fast pyrolysis application. Chemical Engineering and Processing - Process Intensification 130:67-75. doi:https://doi.org/10.1016/i.cep.2018.05.023 160. Jurtz N, Kraume M, Wehinger Gregor D (2018) Advances in fixed-bed reactor modeling using particle- 